QUALITY-ASSURANCE PLAN FOR THE ANALYSIS OF FLUVIAL SEDIMENT BY LABORATORIES OF THE U.S. GEOLOGICAL SURVEY

By Wilbur J. Matthes, Jr., Clyde J. Sholar, and John R. George

U.S. GEOLOGICAL SURVEY

Open-File Report 91-467

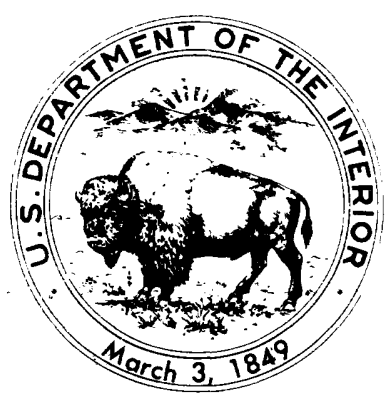

Iowa City, Iowa

1992 
U.S. DEPARTMENT OF THE INTERIOR

MANUEL LUJAN, JR., Secretary

U.S. GEOLOGICAL SURVEY

Dallas L. Peck, Director

For additional information write to:

Copies of this report can be purchased from:

District Chief

U.S. Geological Survey

Rm. 269, Federal Building

400 South Clinton Street

Iowa City, Iowa 52244
U.S. Geological Survey

Books and Open-File Reports

Denver Federal Center

Box 25425

Denver, Colorado 80225 


\section{CONTENTS}

Page

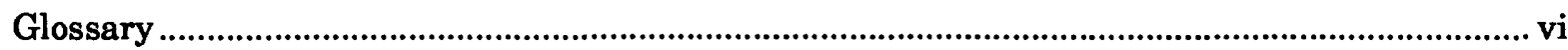

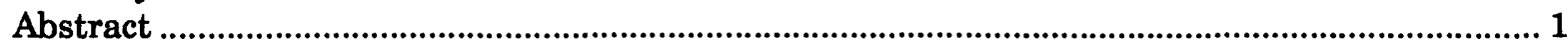

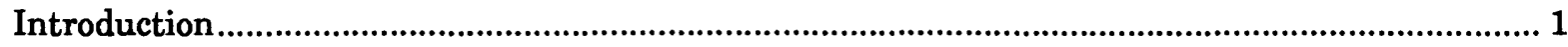

Quality assurance of laboratory instruments and equipment, field and laboratory glass and plasticware ............................................................................................................................. 1

Instruments and equipment............................................................................................. 1

Computer hardware and software for sediment analyses ........................................ 2

Balances..................................................................................................................... 2

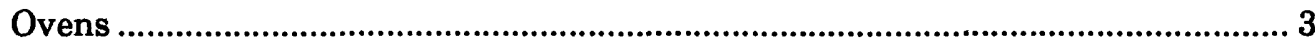

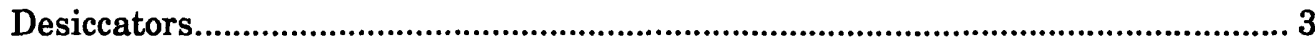

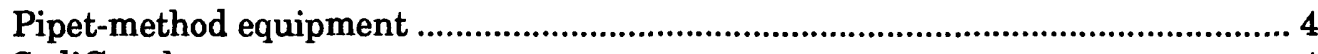

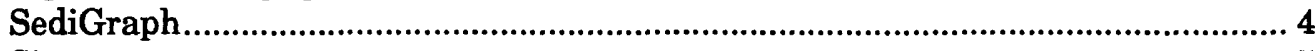

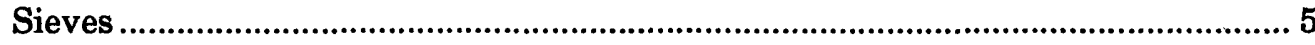

Visual-accumulation-tube equipment.......................................................................... 5

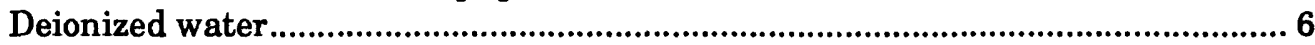

Specific-conductance meters....................................................................................... 6

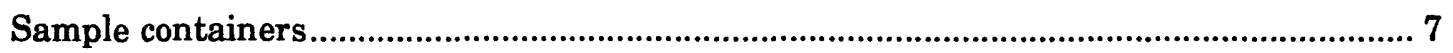

Field sample containers........................................................................................... 7

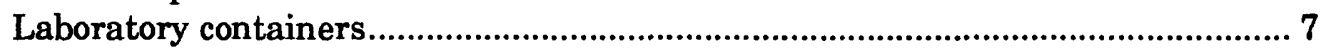

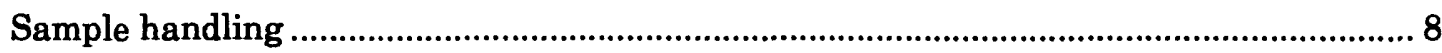

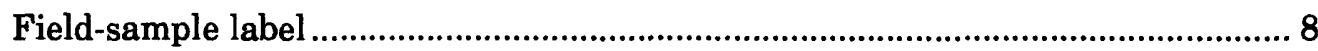

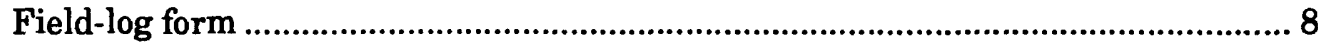

Field-shipment $\log$ form...................................................................................... 8

Field shipment of samples ................................................................................... 9

Sample storage …………………………………………………………………. 9

Login of samples............................................................................................................... 12

Login of samples for concentration analysis..................................................................... 12

Login of samples for particle-size analysis ...................................................................... 14

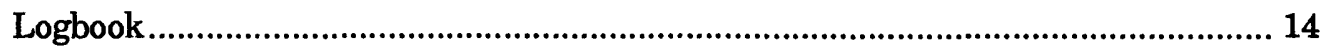

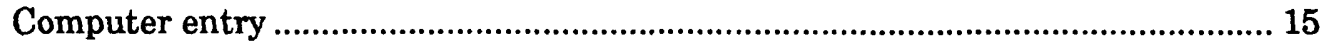

Quality assurance of analytical procedures..................................................................................... 15

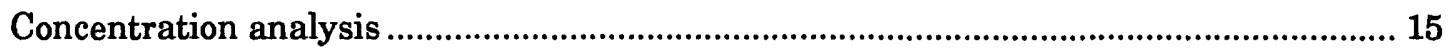

Particle-size analysis ..................................................................................................... 18

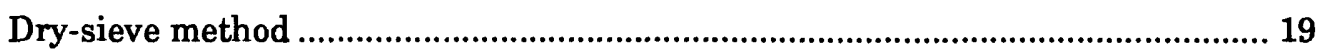

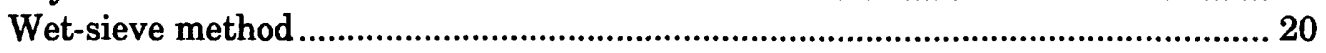

Visual-accumulation-tube method .................................................................. 21

Pipet method ......................................................................................................... 24 


\section{CONTENTS-.Continued}

Quality assurance of analytical procedures-Continued

Particle-size analysis--Continued

SediGraph method 28

Internal quality-assurance and quality-control procedures

Login records

Check samples.

Data procedures

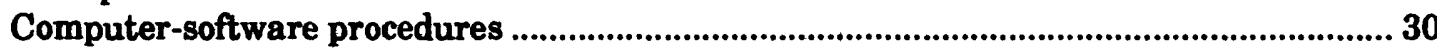

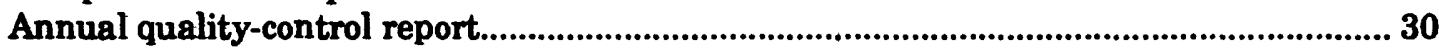

Training 30

Selected references..

\section{ILLUSTRATIONS}

Figure 1. Photograph of a sediment-laboratory work station with terminal and analytical balance connected to computer.

2. Photograph of a sediment-laboratory drying oven .................................................. 3

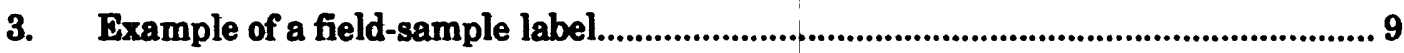

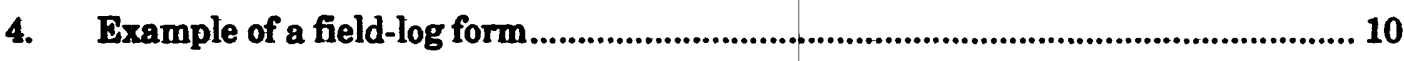

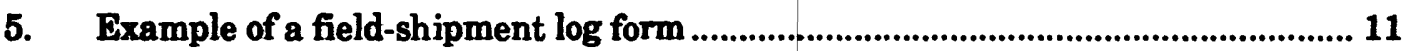

6. Example of computer-generated results for suspended-sedimentconcentration analyses......................................................................................................... 13

7. Example of computer-generated results for particle-size analysis of bed material using dry-sieve method.

8. Photograph of visual-accumulation tubes with automatic tracking devices installed in laboratory.

9. Example of computer-generated results for complete particle-size analysis of suspended sediment using pipet and visual-accumulation-tube methods. 


\section{CONVERSION FACTORS AND ABBREVIATIONS}

Multiply

inch (in.)

ounce, fluid (oz)

pint (pt)

quart (qt)

gallon (gal)

degree Fahrenheit $\left({ }^{\circ} \mathrm{F}\right)$

pound per square inch $\left(\mathrm{lb} / \mathrm{in}^{2}\right)$

parts per million ${ }^{1}$ (ppm)
By

Length

2.54

\section{Volume}

0.2957

0.4732

0.9464

3.785

\section{Temperature}

$$
{ }^{\circ} \mathrm{C}=5 / 9\left({ }^{\circ} \mathrm{F}-32\right)
$$

\section{Pressure}

$$
6.895
$$

kilopascal

\section{Concentration (Mass/Volume)}

1.0

\section{To obtain}

centimeter

liter

liter

liter

liter

degree Celsius $\left({ }^{\circ} \mathrm{C}\right)$

1 This conversion is true for:

$$
\mathrm{mg} / \mathrm{L}=\text { Concentration }(\mathrm{ppm})=\text { Concentration }\left[\frac{\text { Weight of sediment } \times 10^{6}}{\text { Weight of water-sediment mixture }}\right]
$$

when the ratio of weight of sediment $\left(\mathrm{x} 10^{6}\right)$ to weight of water-sediment mixture is between 0 and 8,000 . If this ratio is greater than 8,000 , the investigator is referred to Quality of Water Branch Technical Memorandum No. 72.10, tables 1 and 2, for the correction conversion factor to be used in the formula (Edwards and Glysson, 1988). 


\section{GLOSSARY}

Accuracy--A measure of the degree of conformity of the mean value obtained by using a specific method or procedure with the true value. The concept of accuracy includes both bias (systematic error) and precision (random error) (Friedman and Erdmann, 1982).

Bias--A persistent positive or negative deviation of the mean value obtained by using a specific method or procedure from the true value. In practice, bias is expressed as the difference between the accepted true value and the mean value obtained by repetitive testing of a homogeneous sample.

Malt mixer--A malted-milk mixer unit used for mechanical mixing of material finer than $0.062 \mathrm{~mm}$ (millimeters) before bottom-withdrawal tube or pipet-method analysis.

Precision--The degree of agreement of repeated measurements of a homogenous sample by a specific procedure, expressed in terms of dispersion of the values obtained about the mean value (Friedman and Erdmann, 1982).

Quality assurance--A term used to describe programs and the sets of procedures, including (but not limited to) quality-control procedures, which are necessary to assure data reliability. With regard to the analysis of fluvial sediment the term includes both practices used by personnel outside the laboratory and practices used by personnel of the laboratory to assure the quality of laboratory data (Friedman and Erdmann, 1982).

Quality control--A term used to describe the routine procedures used to regulate measurements and produce data of satisfactory quality (Friedman and Erdmann, 1982).

Reanalyzed sample fractions--Whole or parts of samples that have been reanalyzed and may be reanalyzed using the same method for reproducibility of results.

Reference samples--Prepared sediment samples of known particle-size distribution or of a known weight. These samples are provided to laboratories or are produced in the laboratory as a part of the quality-assurance program.

Replicate sample--A second field-collected sample; collected using the same method of collection at the same location and at nearly the same time.

Sample blank--Samples consisting of deionized water that are inserted into the analyses routine. A sample blank verifies accuracy and precision of the laboratory balances and the quality of the deionized water and is a part of quality-control program.

Soil-dispersion cups--Malt-mixer cups modified to better disperse a sample for particle-size analysis using the bottom-withdrawal tube or pipet methods.

Split sample--A part of a sample separately analyzed for comparison of results.

Standard solution--A fluid that is mixed to produce a specific value when it is tested with measurement instruments. It is used to check and calibrate the instruments.

Tare weight--The weight of an empty sample container. 


\title{
QUALITY-ASSURANCE PLAN FOR THE ANALYSES OF FLUVIAL SEDIMENT BY LABORATORIES OF THE U.S. GEOLOGICAL SURVEY
}

By

\author{
Wilbur J. Matthes, Jr., Clyde J. Sholar, and John R. George
}

\begin{abstract}
This report describes procedures used by the Iowa District sediment laboratory of the U.S. Geological Survey to assure the quality of sediment-laboratory data. These procedures can be used by other U.S. Geological Survey laboratories regardless of size and type of operation for quality assurance and quality control of specific sediment-laboratory processes. Also described are the equipment, specifications, calibration and mantainance, and the protocol for methods used in the analyses of fluvial sediment for concentration or particle size.
\end{abstract}

\section{INTRODUCTION}

The U.S. Geological Survey operates several sediment laboratories throughout the United States. A few laboratories perform sediment analyses for suspended-sediment concentration, determination of percentage sand and finer material, and complete particle-size analyses for suspended and bed-material sediment. The remainder of the laboratories analyze sediment samples only for suspended-sediment concentration and do only limited particle-size analysis. To ensure that all types of analyses performed in all laboratories are accurate and uniform, standard analytical procedures, as described by Guy (1969), must be followed and the procedures documented.

This document sets forth a quality-assurance plan for sediment laboratories to ensure that standard procedures are being followed. The plan incorporates the analytical methods normally used in a sediment laboratory. The path of the sediment sample through a laboratory is described, from receiving the sediment sample at the loading dock, through the analytical processes, to compiling results of the requested analyses. This quality-assurance plan is described in the context of the sediment laboratory operated by the Geological Survey in Iowa City, Iowa. The laboratory is operated on a full-time basis with a permanent staff of two persons and a part-time staff that varies between 3 and 6 persons. Members of the part-time staff generally are students in post-high school institutions, hired under special Federal hiring programs for students. About 15 percent of the laboratory operating funds are dedicated to quality control.

The reader is assumed to be familiar with basic sediment analytical techniques. This manual sets forth the requirements for quality assurance and control as the user performs the various analyses in a sediment laboratory.

\section{QUALITY ASSURANCE OF} LABORATORY INSTRUMENTS AND EQUIPMENT, FIELD AND LABORATORY GLASS AND
PLASTICWARE

This section is divided into two major topics. The first section discusses the instruments and equipment used in the laboratory. This includes the use of logbooks and the processes of documenting the calibration and maintenance of the instruments and equipment. The second section describes the containers used in the field and laboratory. Described are various processes that can be used with these items to help ensure the validity of the sediment analysis.

\section{Instruments and Equipment}

The instruments and equipment used in the laboratory that are discussed in this section are computers and computer software, balances, drying ovens, desiccators, equipment used in the pipet method of sediment analysis, SediGraph ${ }^{1}$, sieves, visual-accummulation-tube equipment, and specific-conductance meters.

1 The use of brand names in this report is for identification purposes only and does not constitute endorsement by the U.S. Geological Survey. 


\section{Computer Hardware and Software for Sediment Analyses}

The computer is an essential tool in the sediment laboratory. The computer programs, or software, that record the data from different instruments, process it, and store it, greatly affect the quality of sediment-analysis data. Human errors with respect to the recorded values are reduced considerably by this equipment.

The computer is maintained by the Iowa District computer section and by a companytrained specialist when required. The programs are modified by the Iowa District computer section when needed because of changes in hardware or analytical processes. The computer programs are tested by processing a sample for which the analytical results are known. The results from the predetermined entry are compared with the computer-entry results. Any difference in the results of the computer output would indicate a problem in the computer hardware or software.

\section{Balances}

Two types of balances are used in the sediment laboratory. The macro balance is used to weigh items weighing $100 \mathrm{~g}$ (grams) or more, such as sample containers with or without the water-sediment mixture. The precision of the macro balance is $\pm 0.5 \mathrm{~g}$ (plus or minus $0.5 \mathrm{gram}$ ). The analytical balance is used to weigh items weighing less than $100 \mathrm{~g}$, such as crucibles and evaporating dishes. The required precision of the analytical balance is $\pm 0.5 \mathrm{mg}$ (milligram). The analytical balance has a protective hood over the weighing pan to minimize air-current disturbances of the weighing pan (fig. 1). The balances are fitted with RS232 connectors to enable data transfer directly to a computer.

Balance calibrations are checked each day prior to use. Macro balances are checked with at least two Class $S$ weights, traceable to the National Bureau of Standards (Friedman and

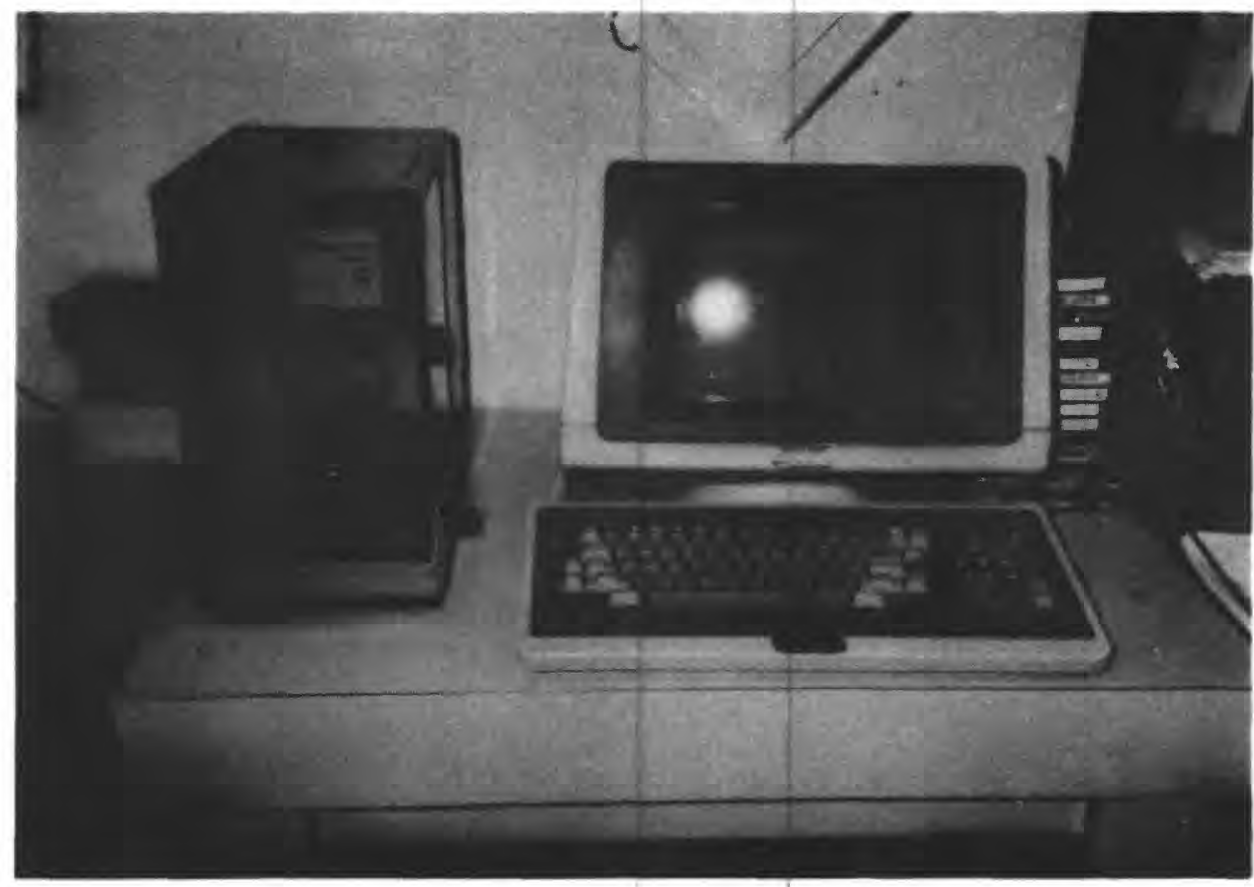

Figure 1. Sediment-laboratory work station with terminal and analytical balance connected to computer. 
Erdmann, 1982), in the range of weights of the anticipated samples. The macro balances are recalibrated if there is an error of more than \pm 0.5 g. Analytical balances are checked with at least two Class S traceable weights in the anticipated range of weights. The analytical balances are recalibrated if the measured weight deviates more than $0.001 \mathrm{~g}$ from the standard weight. The balance is serviced by a service representative if calibration does not bring it within required tolerances.

In addition to the daily checks by laboratory personnel, the laboratory chief checks the balances weekly with Class S weights to verify their accuracy. The balances are serviced and calibrated by a service representative using National Bureau of Standards traceable weights at least once a year. All balance checks, calibrations, and professional servicing for each balance are recorded in the instrument logbook. The analyst compares the weight displayed on the balance with the weight displayed on the computer terminal screen to confirm all entries. The empty balance is checked for a zero reading between each weighing.

\section{Ovens}

Convection-type drying ovens are used to dry the sediment contained in crucibles and evaporating dishes (fig. 2). The ovens are required to maintain a temperature of $103^{\circ} \mathrm{C} \pm 2$ ${ }^{\circ} \mathrm{C}$.

The oven thermometers are checked semiannually at 80 and $110^{\circ} \mathrm{C}$ (American Society of Civil Engineers, 1975) against a calibration thermometer. The oven thermometers are replaced if they differ by more than $2^{\circ} \mathrm{C}$ from the calibration thermometer. The values and action taken are recorded in the oven logbook. Oven temperatures are checked twice during each operation. The values are recorded in the oven logbook. Some reduction in oven temperature may occur when drying large quantities of samples. This is acceptable as long as drying times are extended to allow for complete drying of the sediment.

\section{Desiccators}

Desiccators are used to store crucibles and evaporating dishes after removal from the drying oven to prevent the sample from reabsorbing

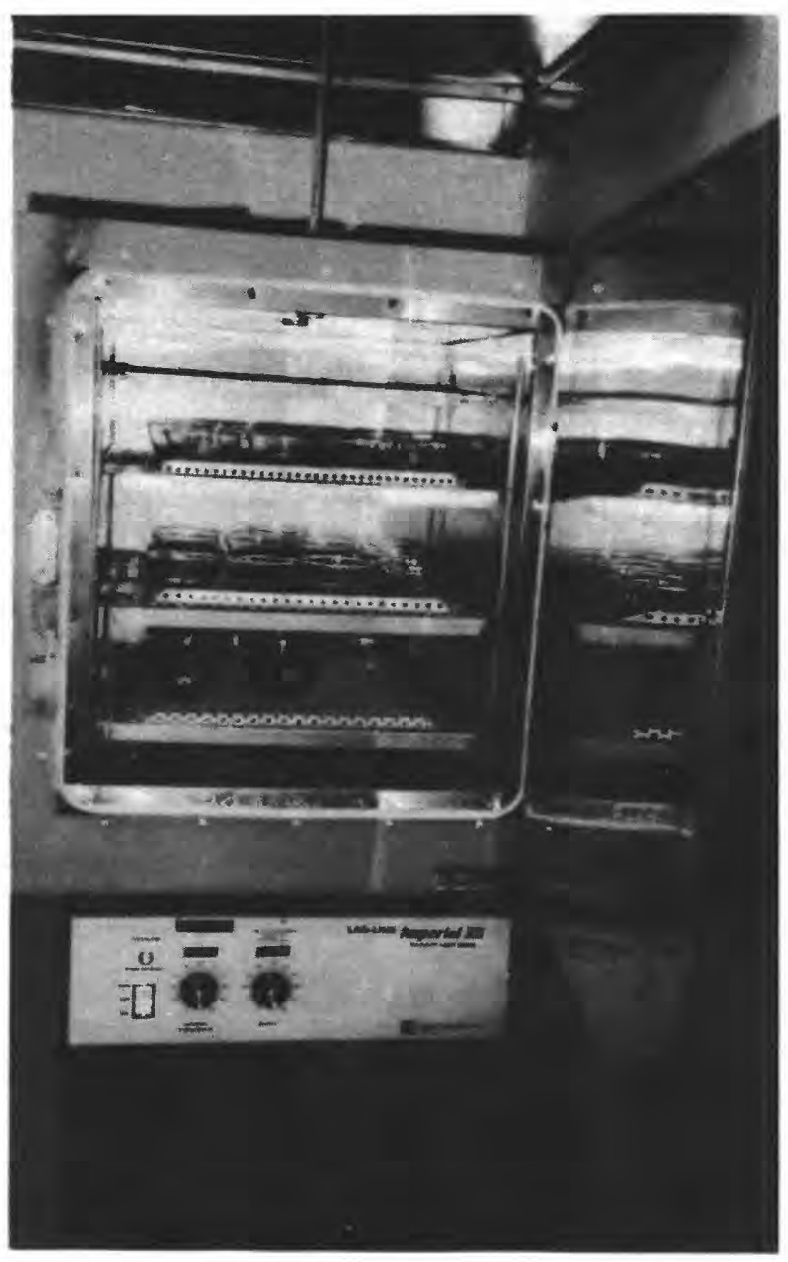

Figure 2. Sediment-laboratory drying oven.

moisture from the air during cooling. The desiccators are checked for moisture buildup each time they are used. A desiccant with a color indicator is used to monitor moisture, and it is replaced when the color indicator shows excessive moisture. The desiccant can be reused by drying in an oven until its original color is restored. Each time the desiccator is used, the sealing surfaces are inspected, and a small quantity of desiccator grease is added as required to ensure a proper seal.

Twice a year the desiccant and sealant grease are removed, and the desiccator is washed with a laboratory detergent. The desiccant is dried, and new dessicant or indicator is added as needed. The date of the last cleaning and the date for the next cleaning are written on the desiccator with a waterproof pen. The date of desiccant change is 
recorded in the desiccator logbook.

\section{Pipet-Method Equipment}

Pipet-method equipment is used to analyze material finer than $0.062 \mathrm{~mm}$ (millimeters). The pipet holds about $25 \mathrm{~mL}$ (milliliters) of watersediment mixture. Each pipet is rated for the volume of solution it will hold. Six withdrawals of deionized water are made with the pipet filled to the stopcock and emptied into pretared evaporating dishes. The weight of the dish and the deionized water are obtained as soon after the withdrawal as possible. The dish weight is subtracted from the weight of the water and dish. The high and low values are discarded. The weights of the water must agree to within 0.5 percent. The remaining weights are totaled and divided by four. This average weight is converted to milliliters. This is then used as the average volume of the particular pipet. Each time a pipet is replaced, a new average volume is determined. The pipet number, dish weights, and calculations are recorded in the pipet-method logbook.

A vacuum system is attached to one stem of the pipet, and the sample deionized-waterrinsing system with air bulb is attached to the other stem. This facilitates the emptying of the sample and flushing the pipet between aliquot withdrawals during the analysis.

The sedimentation cylinders in the pipet method are graduated cylinders ranging in volume from 250 to $1,200 \mathrm{~mL}$. The cylinders are made of either glass or plastic. The cylinders are checked for the correct volume by weight. The empty cylinder is weighed, filled with deionized water at a temperature of $25^{\circ} \mathrm{C} \pm 1^{\circ} \mathrm{C}$ to the manufacture's volume mark, and then reweighed. The empty-cylinder weight is subtracted from the filled-cylinder weight to determine the weight of the water. The water weight is compared with the indicated volume. If the difference exceeds 0.5 percent, a new mark of the correct volume by weight is made on the cylinder. The process is repeated for each cylinder, and results are recorded in the pipetmethod logbook.

During the pipet analyses, the cylinders with the water-sediment mixture are placed in a constant-temperature water bath. The water bath has a volume of about 25 gal and will hold seven sedimentation cylinders. A heating element with a temperature control maintains the temperature in the water bath. If the ambient temperature is stable, the non-heated water bath will maintain the cylinder temperature within $\pm 0.5^{\circ} \mathrm{C}$ during the analysis. If the ambient temperature varies, the water-bath temperature is set $2{ }^{\circ} \mathrm{C}$ above the highest ambient temperature for the analysis. The before and after temperatures of the water bath and cylinders are recorded on the analysis worksheets.

A vacuum system attached to the pipet is used to make aliquot withdrawals during the analysis. The system is equipped with a vacuum gage and a bleeder-valve control that enables adjustment of the vacuum and thus maintains a correct withdrawal time. The required rate of withdrawal fills the pipet in 12 seconds when the stem of the pipet is immersed to a depth $15 \mathrm{~cm}$ (centimeters). This rate is checked before analyzing each set of pipet samples.

\section{SediGraph}

The SediGraph is an automated particle-size analyzer for material finer than $0.062 \mathrm{~mm}$. The initial settings of the SediGraph require the analysis of the base solution to obtain the zero or baseline setting. The base solution is $1 \mathrm{~mL}$ of dispersing agent added to each $100 \mathrm{~mL}$ of deionized water. The dispersing agent is made by dissolving $7.94 \mathrm{~g}$ of sodium carbonate in deionized water and diluting to 1-L (liter) volume. The dispersing-agent $\mathrm{pH}$ should be from 9.0 to 9.5 , and the agent should be clear. A dissolved-solids correction for the dispersing agent is determined each time the solution is prepared (Guy, 1969). The specific gravity of the material, the starting size of the largest particle based on a sieve analysis, and the sample temperature during the analysis are the other items required to make the initial settings. The sample is placed in a low-wattage ultrasonic water bath for 15 minutes before the analysis to disaggregate the sample before the analysis.

Each day that the SediGraph is used, the instrument is checked with the manufacturer's quality-control cell window and beam-split test. The test assures that cell windows are parallel and that the movement of the sample cell is set correctly. The test uses the base solution for samples, $100 \mathrm{~mL}$ of deionized water mixed with 1 
$\mathrm{mL}$ of dispersing agent. The intensity dial is set to read 48 milliamps with the base solution. Upon completion of the cell-window test, the sample cell-drive mechanism moves the sample cell downward so that the top of the sample cell occludes approximately 50 percent of the X-ray beam intensity, and the intensity dial will read from 23 to 25 milliamps if set correctly. If needed, corrective adjustments are made according to instructions in the SediGraph manual if the zerobaseline test results are not within 3 percent or if the intensity dial does not read from 23 to 25 milliamps after the beam-split test. The zerobaseline and beam-split test are rerun, and the laboratory chief is notified if zero baseline varies more than 3 percent or the intensity dial does not read from 23 to 25 milliamps after the tests. Results of the tests and the corrective actions are recorded in the SediGraph logbook.

The 0 percent setting of the base solution is checked after analyzing 10 samples. One sample in 10 is reanalyzed. If results do not agree within \pm 3 percent in any size class, the previous sample is reanalyzed. If the results do not agree within \pm 3 percent in any size class, the laboratory chief is notified. Results and corrective action are recorded in the SediGraph logbook.

The garnett reference sample is analyzed quarterly. If results are not within \pm 1.5 percent, the calibration of the SediGraph is reset according to manufacturer's instructions, and the reference sample is analyzed again. If results are not within $\pm \mathbf{1 . 5}$ percent, the laboratory chief is notified. Results of the reanalyzed samples, reference-sample analysis, and corrective actions are recorded in the SediGraph logbook.

Normally, 1 sample in 20 is analyzed using both the SediGraph and pipet method. Copies of the results are retained, and the analysis results are entered in the SediGraph logbook.

\section{Sieves}

Sieves are generally used to determine the particle-size distribution of material that is larger than $0.062 \mathrm{~mm}$. Two sets of 8-in. sieves are maintained for determining particle sizes according to the standard U.S. Geological Survey scale (Guy, 1969). Two other sets of 8-in. sieves are maintained for determining particle-size distributions according to other scales when requested. A Rotap machine is used to agitate the sieves during an analysis.

The sieves are inspected before each use for clogging of the screen with particles. If a sieve is estimated to have more than 25 percent of the surface area clogged with material, it is cleaned with an ultrasonic cleaner. A sieve that cannot be cleaned is replaced. The wire cloth must be taut in the sieve. When the wire cloth becomes baggy, the sieve is replaced. As long as the sieves retain a taut wire mesh without tears and are not clogged with material, the wire mesh will retain the integrity of the screen size (Tyler Industrial Products, 1976). Brass or nylon brushes are used for routine cleaning of sieves during analysis. The sieves are inspected after each analysis for tears in the wire cloth. This is especially important in the finer mesh sieves. Small tears that do not affect the tautness of the wire mesh can be repaired with solder. One sample in 20 is reanalyzed, or the sample is split and analyzed for particle-size distribution. If the sizedistribution differs by more than 3 percent in any size class, the sample is reanalyzed. If the size distribution in any size class differs by more than \pm 3 percent, the laboratory chief is notified. The reanalyzed sample results and corrective actions are recorded in the sieve logbook.

\section{Visual-Accumulation-Tube Equipment}

The VA-tube (visual-accumulation tube) is used to analyze sand particle sizes from 0.062 to $2.0 \mathrm{~mm}$. The VA-tube equipment consists of a glass tube from 120 to $180 \mathrm{~cm}$ in length. The diameters of the accumulation chambers in the $120-\mathrm{cm}$ tubes are $2.1,3.4,5.0$, and $7 \mathrm{~mm}$, and the diameter of the $180-\mathrm{cm}$ tube accummulation chamber is $10.0 \mathrm{~mm}$. A chart, calibrated for VAtube analysis, is mounted on a circular drum. A viewing scope and photoelectric cell are connected to the chart-pen assembly. During the analysis, the viewing scope, photoelectric cell, and chart pen are moved upward by hand, or the mechanism is driven upwards automatically by the photoelectric cell activating an electric motor maintaining alignment with the top of the accummulated sand. The pen draws an analog curve on the calibrated chart during the analysis. The VA-tube equipment used in the Iowa laboratory has been modified by installing linear potentiometers to the viewing mechanism and a single board computer with an analog-to-digital converter, which converts the electrical changes 
during the analysis to percentage of sample units for the size distribution.

Before each set of analyses or when the tubes are changed, the tube, rubber connecting tube, and funnel section are dismounted, washed with detergent, and rinsed thoroughly with deionized water to remove detergent residue. After reassembly, the top reference mark on the mounting board is aligned with the reference mark on the funnel, and the top-of-the-tube stopper is aligned with the bottom reference mark on the mounting board. After each analysis, the tube assemblies are rinsed with deionized water. Chart-drum rotation is verified once each day the VA-tube is used. If the timing marks do not line up correctly, the mechanism is cleaned, lubricated, and checked again. If the marks fail to line up again, the laboratory chief is notified. Verification results and corrective actions are recorded in the VA-tube logbook.

Each day samples are analyzed by the VAtube method, one sample is reanalyzed. If there is more than \pm 3-percent difference in any size class, the laboratory chief is notified. Results of the reanalyzed sample and corrective actions are recorded in the VA-tube logbook.

\section{Deionized Water}

Deionized water is used in the laboratory to prevent the addition of dissolved solids when the sediment sample is rinsed into a crucible or evaporating dish or during wet-sieving. Deionized water is demineralized by passage through a mixed cation-anion exchange resin or by distillation. If deionized water is prepared by the laboratory, manufacturer's instructions should be followed. The specific conductance of deionized water at $25{ }^{\circ} \mathrm{C}$ must not exceed 10 $\mu \mathrm{S} / \mathrm{cm}$ (microsiemens per centimeter). Specific conductance of the deionized water is measured weekly, and the readings are recorded in the logbook. An alert light installed in the deionizedwater line helps make the laboratory staff aware that the quality of the water is beginning to deteriorate. The light is on when the water is acceptable to use and off when limits are exceeded.

Storage bottles for deionized water require periodic cleaning with deionized water and liquid bleach to remove organic buildup. The specific steps in cleaning the storage containers may vary according to their size and shape. A container that can be handled by hand is cleaned by adding water, liquid bleach, and laboratory detergent. The solution is mixed in the bottle using $8 \mathrm{oz}$ of liquid bleach to $5 \mathrm{gal}$ of water. Detergent is added at the manufacturer's recommendation for each gallon of water used. The bottle is agitated and allowed to soak for 5 minutes. This procedure is repeated at least three times. A brush is used to remove foreign material. The bottle is rinsed several times with deionized water to remove soap residue.

\section{Specific-Conductance Meters}

A specific-conductance meter is used to measure the specific conductance of sediment samples. The units of specific conductance are microsiemens per centimeter measured at $25^{\circ} \mathrm{C}$ $(\mu \mathrm{S} / \mathrm{cm})$. The precision of the specific-conductance meter used in the sediment laboratory is at least $\pm 5 \mu \mathrm{S} / \mathrm{cm}$. The probe used with the meter may be the plastic-immersion or flow-through type. Because of the fragile nature of glass-immersion probes, they are not recommended for use in the sediment laboratory.

Each day prior to use, the meter calibration is checked with two standard solutions in the range of the anticipated sample specific conductance. The meter is recalibrated if more than a 3 percent difference exists between the values of the standard solutions. Meter linearity is checked weekly using three standard solutions in the range of anticipated sample conductance. Every 3 months the laboratory chief checks the meter with standards to verify meter operation. All calibrations are recorded in the specificconductance meter logbook. When the meter readings differ 5 percent from the standards, the probe should be cleaned or replaced following the manufacturer's suggested procedures. Sedimentlaboratory personnel participate in the nationwide U.S. Geological Survey qualityassurance test for specific conductance conducted by the Survey's National Water-Quality Laboratory in Arvada, Colorado.

Specific-conductance standard solutions are stored in tightly capped containers to avoid contamination and evaporation. Extreme care is taken to avoid contamination. Once the solution is poured out of the original container, it is not poured back whether or not it is used. All 
standards are labeled with an expiration date and are not to be used after that time. Specificconductance standards may be obtained from the U.S. Geological Survey's National Water-Quality Laboratory in Arvada, Colorado, from the U.S. Geological Survey in Ocala, Florida, and from commercial suppliers.

\section{Sample Containers}

Sample containers are of two types: containers for field use and laboratory containers. The sample containers for field use will be discussed first and laboratory containers discussed second.

\section{Field Sample Containers}

Sediment samples are collected in many types of sample containers, depending on the type of sampler used. The 1-pt glass "milk" bottle and 1-qt glass or plastic "mayonnaise" jar are the containers most frequently used in standard U.S. Geological Survey depth-integrating and point samplers. Many automatic samplers use plastic or glass containers of various sizes and shapes.

Empty sample bottles are weighed on the macro balance. The tare weight, to the nearest $0.1 \mathrm{~g}$, is marked on sample bottles before shipment to field offices for use. The weight is etched on a glass bottle with an etching tool or jack frost, a chemical glass-etching solution, and marked on a plastic bottle with paint or a permanent waterproof marker.

Sample bottles are rinsed with 5-percent $\mathrm{HCl}$ (hydrochloric acid) solution if a clouding or buildup of material is seen, and then washed with tap water and a bottle brush. The bottle brush is spun by an electric motor. The shape of the bottle brush allows it to be used to wash most laboratory glassware and glass bottles. If the containers have been exposed to oil, grease, or other hard-to-remove material, a low-residue general-purpose laboratory detergent is used. A thorough rinse in tap water removes detergent and any residue. The bottles are stacked upside down on a bottle rack and air dried. The dried bottles are inspected for cleanliness and rewashed if necessary before packing into shipping cases. The glass bottles are checked for chipped glass; if chips are found, the bottle is discarded. Plastic bottles are examined for cracks that may cause leakage.
Plastic bottles, depending on shape and style, generally are more difficult to clean. Most plastic containers are opaque, which causes some difficulty in visual detection of material on the inside of a container. If a buildup is seen, the bottle is rinsed with a 5-percent $\mathrm{HCl}$ solution, washed with laboratory detergent, and the interior brushed manually. A machine brush is not used because many plastics will scratch, and sediment can become trapped in the etch marks during the next usage. The bottle is thoroughly rinsed in tap water to remove detergent residue.

Five percent of the cleaned, dry containers are weighed to confirm their tare weights. If there is a difference of more than $\pm 1 \mathrm{~g}$ on any bottle from the set, another 3 percent are weighed. If any bottle from this set is determined to have a difference of more than $\pm 1 \mathrm{~g}$, all containers from that group are retared.

\section{Laboratory Containers}

Evaporating dishes are used as laboratory containers for the sample or aliquots during the analytical processes. The dishes are made of Pyrex glass or porcelain that can be placed in the oven for the drying of the sediment or the sample aliquot. The dishes are washed using the bottle brush, rinsed in tap water, and air or oven dried. A laboratory detergent is used to wash the dishes if the brush does not remove the attached material. The dishes are stored in stacks of three in closed drawers. The dishes are weighed to the nearest $0.0001 \mathrm{~g}$ before each use. The dishes are stored in a laboratory pan and covered with a clean, lint-free cloth to prevent contamination when they are not in the drawers.

Filtering crucibles are used to filter samples or aliquots during sample analysis. The crucibles, with bottom diameters of $2.4-4.0 \mathrm{~cm}$, normally contain from 30 to $50 \mathrm{~mL}$ of solution. The filter allows passage of clear liquid and dissolved solids; the sediments collect on the filter disk. The filter crucible is used for those samples or aliquots that have lesser quanities of fine sediments. If the quantity of fine sediment is too great, the filter will become clogged, and some liquid will be retained in the crucible. Two types of filtering crucibles commonly are used: a Pyrextype glass-filtering crucible with an integral fritted-glass disk, or the Gooch-style porcelainfiltering crucible. A glass-fiber filter of the correct 
diameter for the respective crucible is used. After the filtering is complete, the crucible is set in the oven to dry. The crucibles are washed with a machine brush and rinsed with tap water to remove residue. A laboratory detergent may be used to wash them. New filters are placed in the crucibles, seated with vacuum, and oven dried. The fritted-glass disks require periodic cleaning in an ultrasonic cleaner according to manufacturer's recommended cleaning times. Normally, 15 to 30 minutes in the ultrasonic cleaner is adequate when it is filled with enough water to cover the fritted-glass filter. The time of cleaning will vary with the power rating of the cleaner and the type of material that is clogging the fritted-glass filter. The ultrasonic-cleaning procedure should be done when filtering routine samples exceeds 30 seconds. A 5-percent solution of $\mathrm{HCl}$ also may be used in the crucible cleaning.

The crucible filters are Whatman \#934-AH with a pore size of $0.015 \mathrm{~mm}$. Filters are inserted into the clean crucible, wetted with deionized water, and placed under vacuum before oven drying. The vacuum aids the seating of the filters and helps remove loose fibers. While the filter is under vacuum, it is checked for air escaping around it. If air is escaping, the vacuum is turned off, the filter adjusted and rewetted, and the vacuum turned on again. If the filter does not seat properly, it is replaced with a new filter.

The crucibles with filter are removed from the oven and placed in a desiccator to cool and for storage. Each crucible with filter is weighed to the nearest $0.0001 \mathrm{~g}$ before use.

Frequently, glass or plastic beakers ranging in capacity from 30 to $2,000 \mathrm{~mL}$ are used during particle-size analysis or for drying samples. They are washed using the bottle brush, rinsed with tap water, and air dried with the top down on a drying rack. The tare weight is obtained to the the nearest $0.0001 \mathrm{~g}$ for beakers holding $100 \mathrm{~mL}$ or less, and to the nearest $0.1 \mathrm{~g}$ for beakers holding more than $100 \mathrm{~mL}$. The beakers are stored inverted on shelves in a closed cabinet.

\section{Sample Handling}

The reliability of the analyses provided by the sediment laboratory is affected by the quality of samples received from the field. Information about a samples' collection location and the analysis requested also affect the quality of the data. For a valid analysis it is critical that all information about the sample be with the sample for accurate login and sample analysis.

\section{Field-Sample Label}

The field-sample label (fig. 3 ) is filled out at the time of sample collection. The required label information supplied by the person collecting the sample is the date, river and location, time, gage height (G. Ht.), collection station (Sta.) (box, ice, sample point, grab, or other method), and water temperature (Temp.). Samples from an automatic sampler require the station name, the date the sample set begins, and sequence number 1 on first bottle. If the set is kept together as a set, then only the sequence number is required on subsequent bottles, except for the last bottle when the date the set is removed is put on the label.

\section{Field-Log Form}

The field-log form (fig. 4) is completed by an employee during a visit to service a gaging station and to pick up the samples that have been collected by the observer. The field-log form should be legible and include the information relevant to gaging-station location, sample date or sequence number, and analysis required. General comments about sample condition and pertinent remarks often are valuble to the laboratory or the originating office. There should be a separate field-log form for each river in a shipping or carrying case of samples or one for each set of analyses in the case. The field-log form notes the analysis required and for all of the samples collected by the employee and the observer at a station. The field-log forms are placed in a sealed plastic bag to protect them from damage and are retained with the case of samples. A copy should be retained at the originating office.

\section{Field-Shipment Log Form}

Before samples are sent to the laboratory, the originating office completes the field-shipment $\log$ form (fig. 5). Information to complete the shipment log form can be obtained from the field$\log$ form and verified with a physical count of the samples. The shipment $\log$ form contains basic information to assist laboratory personnel during sorting of the samples. The shipment log forms 


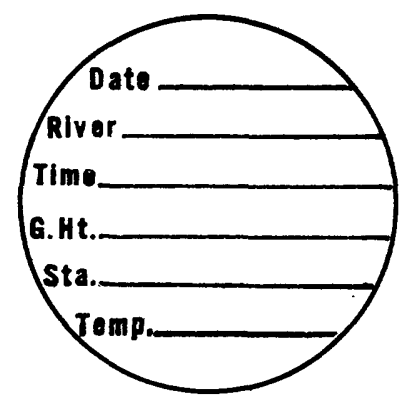

Figure 3. Example of a field-sample label (actual size).

are sent under separate cover to the laboratory. This information then is available to the laboratory personnel when the sample shipment arrives at the laboratory, and each shipping case does not have to opened and searched. The shipment $\log$ form is checked with the number of sample cases received to verify that all of the samples have been received.

\section{Field Shipment of Samples}

Some items to remember when shipping samples to the laboratory follow:

1. Arrange samples in the case in chronological order.

2. Assign case numbers and record the case number on $\log$ form(s) and on the exterior of the case.

3. If samples from more than one station are in the case, record this on the field-shipment log form and on the exterior of case.

4. If different types of analyses are required for samples in a case, record on field-shipment $\log$ form and on the exterior of case. Be sure to include field-log form for each set of bottles in case.

5. Record on the field-shipment log form if the bottles from a cross section or multi-bottle samples are to be composited for analysis or analyzed as discrete samples. If two or more cross sections are collected, indicate those samples for concentration determination and those samples for other analysis and the analysis required. Mark the field-sample labels for a cross section as
“1X-1, 1X-2, $\gg>2 X-1,2 X-2$ " or a similar designation. Include a field-log form for each set of samples in a case.

6. Record the sample shipping date. Laboratory personnel will record the date received and the condition of the samples on arrival. The field-shipment log form will be returned to the customer with notes on the condition of the samples, such as algae, excess water, foreign material, or leakage.

7. Include the name and telephone number of the person responsible for samples on the fieldshipment log form so that questions by laboratory personnel can be resolved quickly.

8. Check to see that the number of samples shipped agrees with the total on the fieldshipment log form.

Normally, few problems are encountered with shipment of samples by freight or the U.S. Postal Service during the warm-weather months. Extra care must be taken when shipping samples during cold weather. Check with the laboratory before sending samples during this time. Freezing can cause minerals to form a precipitate, and the glass bottles can fracture or the plastic bottles split. Any of these conditions will ruin sample validity. The handling of fractured glass bottles by the carrier and laboratory personnel is a potential hazard. Normally, it is best not to ship when air temperatures will be below $32{ }^{\circ} \mathrm{F}$. There are freight companies that use heated trailers. Incidents of samples freezing still occur because local carriers may not have a heated trailer.

The HIF (U.S. Geological Survey Hydrologic Instrumentation Facility) sediment-sample case, a hard plastic case with a foam liner on all sides, is the recommended shipping case for pint and quart glass bottles. These cases must be used if a shipment is sent with the U.S. Postal Service. The sediment cases are available from HIF at Stennis Space Center, Mississippi. Wire cases can be used with most freight carriers, but more breakage occurs when these cases are used.

\section{Sample Storage}

Samples are stored in a cool, dark location when they are received at the laboratory. The samples are allowed to settle for 2 weeks and are 
SEDIMENT SAMPLE FIELD LOG

PAGE of

STATION NUMBER CURRENT DATE CASE NUMBER

RIVER NAME

INITIALS CONDITION OF SAMPLES?

REMARKS:

REMARKS:

$$
\begin{aligned}
& \text { CAN CAPS BE READ? Yes No ARE BOTTLES IN ORDER? Yes _ No } \\
& \text { DID YOU TALK TO OBSERVER? Yes_No_ }
\end{aligned}
$$

\section{CAN CAPS BE READ? Yes}

TYPE OF ANALYSIS: 1) CONCENTRATION ONLY 2) COMPOSITE CONCENTRATION

3) SANDIFINE BREAK 4) COMPOSITE SANDIFINE BREAK 5) PARTICLE SIZE

6) COMPOSITE PARTICLE SIZE 7) OTHER - EXPLAIN IN REMARKS

\begin{tabular}{|c|l|l|l|c|c|c|c|}
\hline $\begin{array}{c}\text { BOTTLE } \\
\text { NUMBER }\end{array}$ & $\begin{array}{c}\text { SAMPLE } \\
\text { DATE }\end{array}$ & $\begin{array}{c}\text { ANALYYSIS } \\
\text { REQUIRED }\end{array}$ & REMARKS & $\begin{array}{c}\text { BOTTLE } \\
\text { NUMBE }\end{array}$ & $\begin{array}{c}\text { SAMPLE } \\
\text { DATE }\end{array}$ & $\begin{array}{c}\text { ANALYSIS } \\
\text { REQUIRED }\end{array}$ & REMARKS \\
\hline 1 & & & & 15 & & & \\
\hline 2 & & & & 16 & & & \\
\hline 3 & & & & 17 & & & \\
\hline 4 & & & & 18 & & & \\
\hline 5 & & & & 19 & & & \\
\hline 6 & & & & 20 & & & \\
\hline 7 & & & & 21 & & & \\
\hline 8 & & & & 22 & & & \\
\hline 9 & & & & 23 & & & \\
\hline 10 & & & & 24 & & & \\
\hline 11 & & & & 25 & & & \\
\hline 12 & & & & 26 & & & \\
\hline 13 & & & & 27 & & & \\
\hline 14 & & & & 28 & & & \\
\hline
\end{tabular}

TOTAL \# OF OBS. SAMPLES

. TECINTCIAN SAMPLES FROM FIXED LOCATION

X-SECTION

START NEW LOG FORM FOR EACH CHANGE OF RIVER, OR CHANGE OF SAMPLING MODE. KFEP FORM(S) NN CASE WITH SAMPLES.

Figure 4. Example of a field-log form. 

OF

DATE OF SHIPMENT DATE RECEIVED CASE/BOX NUMBER STATION NUMBER STATION NAME

TYPE OF SAMPLE: DAILY, EWI, EDI, OTHER - COMPOSITE FOR ANALYSIS YES, NO. TYPE OF ANALYSIS - CONCENTRATION ONLY, SAND/FINE BREAK, COMPLETE SIZE. BEGIN DATE END DATE NUMBER OF BOTTLES REMARKS :

(Circle appropriate response)

CASE/BOX NUMBER STATION NUMBER STATION NAME

TYPE OF SAMPLE: DAILY, EWI, EDI, OTHER - COMPOSITE FOR ANALYSIS YES, NO. TYPE OF ANALYSIS - CONCENTRATION ONLY, SAND/FINE BREAK, COMPLETE SIZE. BEGIN DATE END DATE NUMBER OF BOTTLES

REMARKS :

(Circle appropriate response)

CASE/BOX NUMBER STATION NUMBER STATION NAME TYPE OF SAMPLE: DAILY, EWI, EDI, OTHER - COMPOSITE FOR ANALYSIS YES, NO. TYPE OF ANALYSIS - CONCENTRATION ONLY, SAND/FINE BREAK, COMPLETE SIZE. BEGIN DATE END DATE NUMBER OF BOTTLES

REMARKS :

(Circle appropriate response)

Figure 5. Example of a field-shipment log form. 
analyzed within 60 days from the time they are received. If it is anticipated that a sample cannot be analyzed within this period of time, the weight of the water-sediment mixture of the sample is obtained and recorded to prevent errors because of evaporation. If algal growth is a problem in the sample, it normally occurs prior to receipt by the laboratory, and the customer is advised of this problem. Improper storage of samples before and after the samples are received by the laboratory can cause major problems and possibly complete loss of the sample. Some of the more common problems that occur during sample storage include the growth of algae, dirt and grime accummulation on exterior of the sample bottle, evaporation of water, spillage or breakage of sample, and loss of field-sample label.

\section{LOGIN OF SAMPLES}

Samples received at the laboratory are separated into two groups on the basis of the information received on the field- and fieldshipment $\log$ forms. Samples are grouped by concentration analysis and particle-size analysis.

\section{Login of Samples for Concentration Analysis}

These samples are sorted by station and arranged chronologically so that the sample with the oldest date is the first to be analyzed. The login procedures described are used with a computer program, SED (suspended-sediment concentration computer program), developed by the Iowa District computer section. Documentation for this program is available from the Iowa District office of the U.S. Geological Survey, Iowa City.

Laboratory personnel enter the field data and tare weight of each sample container into the computer. Weighings of the water-sediment mixture and dried sediment during the analysis are made using electronic balances that are connected to the computer and accessed by the SED program. The weights are stored with the field information for each sample.

Use of the computer during processing eliminates errors that are common in manual processing of samples. Entry errors with respect to weights are nearly eliminated using the computer system. Tests are built into the computer software to check the entry of weights, acceptance of the weights in the computer, and the validity of the computations of the results.

The first entry in a new data file is a qualitycontrol, precalculated system-check sample that validates the operation of the computer and software. Thirty-one check-sample entries are available for this validation, one for each day of the month. The results from the check samples cover the normal range of sediment concentrations analyzed by the laboratory. Data are entered from the check sample for the current date. When the final results for a data file are available, the check-sample results from the data file are compared for agreement with the precalculated results of the check sample. Any error would indicate a problem with the computer system or with the sedimentconcentration software program.

The second data entry is the initial login of sample data. The samples are logged in chronological order beginning with the oldest date first. Login of a concentration sample consists of entry of the data from the sample's field-label form, measured specific conductance, bottle tare weight, the weight of the bottle and the water-sediment mixture, and selection of the evaporation or filtration method for analysis. The program stores the data in the data file. The field-log form is checked with the incoming samples and the field-shipment log forms both during initial separation of the samples and during login. Mislabeled or missing samples are noted on the $\log$ forms. If sample information cannot be resolved in the laboratory, the customer is contacted.

During the login process, replicate field samples, reference samples (when available), and sample blanks are entered into the system. About 5 percent of the samples analyzed are qualitycontrol samples.

The laboratory chief is responsible for introduction of the quality-control samples not supplied by the customer. The results of the precalculated system-check sample, sample blanks, and field replicates as shown in figure 6 are printed with the sample analyses on the final results. The definition of some of the items in figure 6 are as follows:

B - laboratory-code input for sample blank 
IOWA DIS. U.S.G.S. SEDIMENT NOTES PROGRAM 5.1 FILE:IA-2-21-90

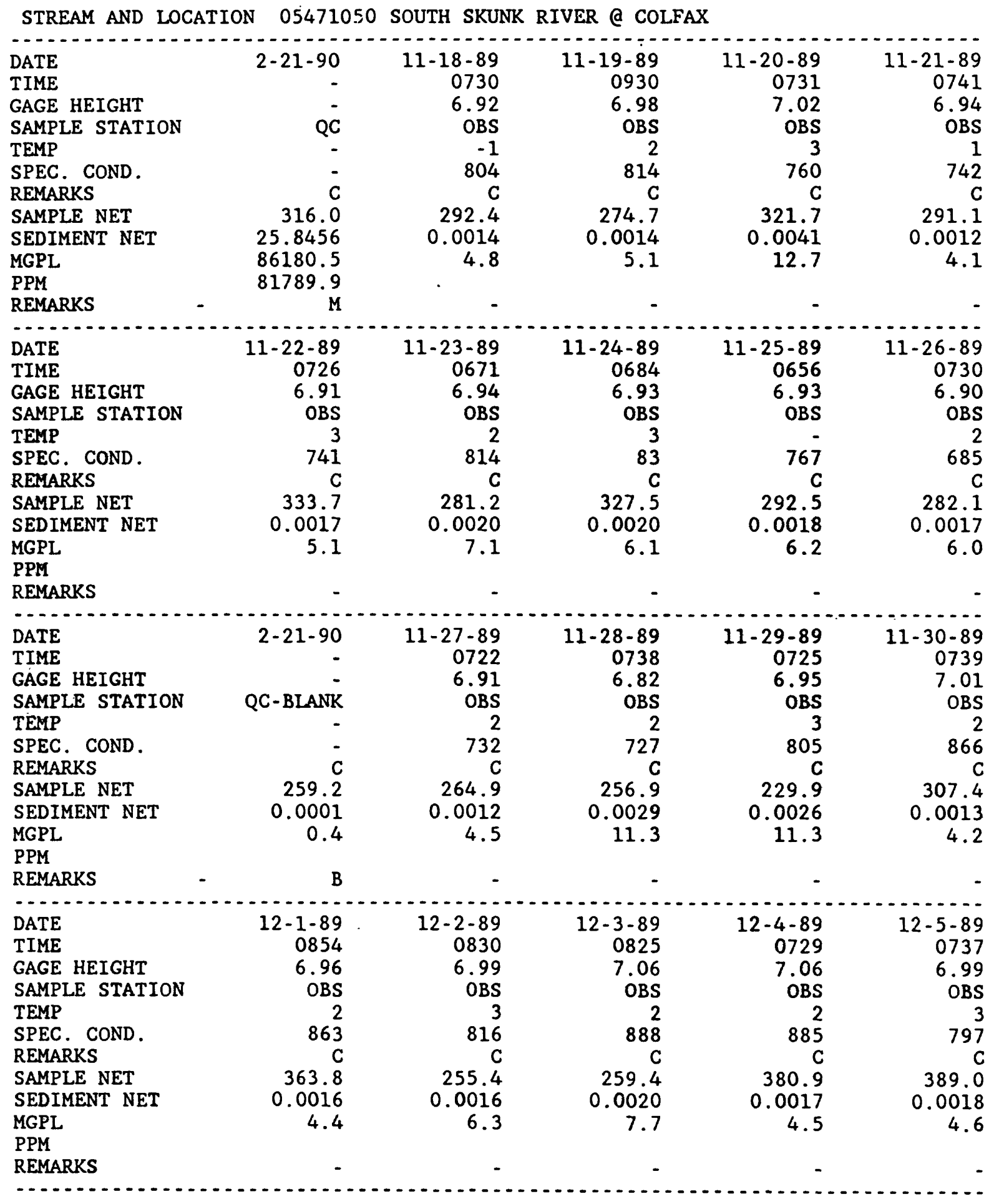

Figure 6. Example of computer-generated results for suspended-sediment-concentration analyses. 
required by the computer software.

C - Crucible used for concentration analysis.

M - laboratory-code input for system-check sample required by the computer software.

MGPL - milligram per liter.

OBS - Observer sample.

PPM - parts per million.

QC - laboratory quality-control sample.

QC-BLANK - a quality-control blank sample of deionized water.

REMARKS - used by the laboratory for special code and notes about sample appearance, such as sand or algae.

SAMPLE NET - weight of water-sediment mixture, in grams.

SEDIMENT NET - weight of sample's dried sediment, in grams.

SPEC. COND. - specific conductance of the sample at time of analysis.

TEMP - water temperature of the sample at time of collection.

All data from the quality-control samples are stored in the data file and can be accessed to produce a graphic or tabular display as part of an annual quality-control report. A listing of station number, stream name(s), the date processed, and the graphic display or listing of the analytical results comprises the quality-control report to the laboratory customers. The laboratory chief is responsible for checking the results from the quality-control samples.

A worksheet is printed by the SED program after the login part of the analysis is completed. The worksheet is used by laboratory personnel during the remainder of the analysis. The data on the worksheet are compared with the sample data for errors that are corrected before the final results are obtained. The worksheet is used to rebuild the data file if the computer malfunctions unexpectedly and the data file is lost.

Available as a part of the computer- generated results are a listing of the rivers in a data file and the number of samples analyzed. The laboratory retains a copy of this listing and records the inclusive dates of the analysis for a $\log$ of the samples analyzed.

\section{Login of Samples for Particle-Size Analysis}

The login process is used to account for the sample in the laboratory. The computer is used to store the data and maintain a record of the analytical status of the sample. The procedures described herein for login, data entry, and obtaining of analysis results for particle-size samples use a computer program called SIZE, which was developed by the Iowa District computer section. Documentation for this program is available from the Iowa District, U.S. Geological Survey.

\section{Logbook}

A logbook is maintained for each customer. The logbook normally is divided into five major sample categories. These categories correspond with the prefix used in the filename for the computer program. The prefix assures that the proper computations are performed for the analysis. A listing of the prefixes and a description of each follow:

1. SF--represents a suspended-sediment sample, analyzed for the percentage of sediment finer than $0.062 \mathrm{~mm}$ and for concentration.

2. SI--represents a concentration analysis and a particle-size analysis that involves one or more of the following methods: a sieve determination for material larger than $0.062,1$, or $2 \mathrm{~mm}$, a VA-tube method for material of sizes between 0.062 and 1 or $2 \mathrm{~mm}$, a pipet or SediGraph method for material finer than $0.062 \mathrm{~mm}$.

3. BM--represents a bed material, bed load, or soils particle-size analysis. The sample would be analyzed using the same methods as SI but would not have a concentration determination.

4. MR--represents analyses similar to SI, with the exception that both the standard U.S. Geological Survey scale and a non- 
standard scale are used for reporting values and a concentration is computed for material larger than $0.062 \mathrm{~mm}$, as well as for the total sediment in the sample.

5. BC--represents a bed-material analysis with a nonstandard scale used for the reporting values.

All samples received by the laboratory for particle-size analysis are logged in one of these categories. Recorded in the logbook is the sample identification number, the date the sample was collected, the station number, stream name, the number of bottles, and the date the sample was logged in. The sample identification number is a unique number comprised of the appropriate prefix for sample type, the water year of sample collection, and next higher number than the last entry. Two letters are added to the unique number that identify the customer. For example, the first suspended-sediment particle-size sample for the Iowa District during the 1990 water year would be SI-9001-IA.

\section{Computer Entry}

The computer entry of the particle-size sample is done as soon as possible after the sample arrives at the laboratory and after an initial 2-week settling period. The entry of the sample information into the logbook and the entry of the field data for the sample into the computer are done at the same time. The unique number in the logbook is the file name of the data file.

The field-data entry and the weighing procedure are similar to the concentration program. After the entered data are compared with the field-shipment log form and the field-log form, a worksheet is requested from the program. The prefix of the unique sample number determines the format of the worksheet. The heading of the worksheet contains the unique number, station number, station name and location, and the information from the field-log form. The format of the worksheet is determined by the specific analysis or types of analyses. Sufficient space is allotted for notes.

\section{QUALITY ASSURANCE OF} ANALYTICAL PROCEDURES

The basic reference of standard methodology for sediment-laboratory operations is U.S. Geological Survey Techniques of WaterResources Investigations, Book 5, Chapter C1 (Guy, 1969). Listed below are the bench-level (laboratory) protocols for concentration determination and particle-size analyses. These protocols include specifics not contained in Guy (1969) and focus on quality control.

\section{Concentration Analysis}

The concentration of suspended sediment is determined in parts per million by dividing the weight of the sediment by the weight of the water-sediment mixture and multiplying the result by $1,000,000$. Two methods may be used for the analysis. Both methods require the clear water be decanted from the sample without disturbance of the settled sediment. The filtration method uses a crucible, a filter, and the vacuum system to dewater the crucible. The sample then is oven dried, cooled, and weighed. The advantage to this method is that the dissolved solids present in the sample will pass through the filter and will not affect the results. A disadvantage is that large quantities of sediment in the sample can clog the filter. The second method is the evaporation method, which uses an evaporating dish to contain the sample. The main disadvantage to this method is the possibility of dissolved solids affecting the results because they are a part of the residue from evaporation. To compensate for this possibility, this method is used only for samples with large quantities of sediment, and care is taken to decant as much clear water from the sample as possible before transfer to the evaporating dish. Specific conductance is measured for all concentration samples so that a determination of dissolved solids can be applied if required by a particular sample. The methods and their quality-control measures are outlined below.

1. Stage 1 of the concentration program.--The sample data are entered into the computer.

1.1. The first entry.--Information for a quality-control computer and system check from a precalculated check sample for the current date is entered.

1.2. The second entry.--The sample login and sample data entry.

1.2.1. Remove cap from first bottle 
and check bottle data with field$\log$ form.

1.2.2. Enter information from the bottle label and bottle tare weight in accordance with program prompts. Bottles should have the tare weight affixed before use. If not, place an identification name with grease pencil on the container and determine the tare weight after washing and drying.

1.2.3. Check balance display between weighings for $0.0 \mathrm{~g}$ tare reading.

1.2.4. Place the sample container on the macro balance.

1.2.5. Measure the specific conductance by inserting probe to waterline mark. When a stable reading is attained, enter the measurement at the computer prompt.

1.2.6. The weight transfer is made by pressing the return key on the computer keyboard at the prompt. When the balance is stable, the letter " $\mathrm{g}$ " is displayed on the balance, and the software transfers the weight displayed on the balance to the data file.

1.2.7. Choose a crucible or evaporating dish.

1.2.7.1. The filtration method is preferred if a ring of sediment collected on the bottom of the bottle is less than $3 / 8$ in. wide.

1.2.7.2. The evaporating dish is used if the quantity of sediment that collects on the bottom of the bottle is larger than $3 / 8$ in. (Guy, 1969).

1.2.7.3. The choice is recorded in the data file by entering $a$ " $C$ " for cruicible or " $E$ " for evaporating dish at the "Remarks" prompt.

1.3. Quality-control measures

1.3.1. The field-log form is compared with data entry to the computer to confirm sample documentation.

1.3.2. The macro balance is connected to the computer, and the data are transferred electronically. Each digital display is compared with the weight entry on the screen to assure validity of the weight.

1.3.3. The macro balance is professionally cleaned and calibrated ennually. Balance calibration is checked daily with a Class " $\mathrm{S}$ " traceable weight set and documented in the balance logbook. The balance calibration is checked weekly with Class S traceable weights by the laboratory chief and recorded in the balance logbook. The 0.0-g empty weight is checked between each weighing.

1.3.4. Quality-control samples comprise about 5 percent of the total samples analyzed and are used to assure and document laboratory and field techniques, quality of deionized water, balance operation, and software and computer operation.

2. Most of the sediment-free water in the bottle is decanted using care not to disturb or remove sediment. A J-shaped tube and vacuum system is used to suction the supernatant water from the top, away from the sediment. Do not tilt the bottle because this may disturb the sediment. Decanting vacuum should not exceed $15 \mathrm{lb} / \mathrm{in}^{2}$ for a 1/8-in. diameter $\mathrm{J}$-tube or $25 \mathrm{Ib} / \mathrm{in}^{2}$ for a 1/4-in. diameter J-tube. 
3. Replace bottle caps and store sample on table or rack. Repeat steps 1 through 3 until all samples have been logged, weighed, decanted, and stored.

4. In stage 2 of the concentration program the crucible and evaporating dishes are weighed.

4.1. The crucibles or dishes should not be moved with unprotected fingers. Use tongs, plastic glove, or rubber fingertip pads. This prevents the transfer of moisture and skin oils to the glassware.

4.2. The software in stage 2 of the concentration program displays the numerical sequence of the sample and the login information and a prompt for the container identification (ID).

4.2.1. The display is reviewed, the appropriate crucible or evaporating dish is selected, and the container ID is entered.

4.2.2. The prompt for container tare is displayed, and the container is placed on the analytical balance. The appearance of the letter " $g$ " on digital display indicates the balance is stabilized, and the "enter" key is pressed. The tare weight of the container is transferred electronically to the data file. The balance display is compared with the transferred weight for all weighings. The empty balance reading is checked between all weighings.

\subsubsection{Step 4 is repeated until all crucibles and evaporating dishes are weighed.}

4.3. A worksheet of the sample entry is printed at completion of stage 2 . This prevents loss of data in case of computer failure. The software updates the sample information to the data file after each sample entry. Before this stage in the sample analyses sufficient information is available to reconstruct the data file in case of computer failure.

\subsection{Quality-control measures.}

4.4.1. Protective devices are used when handling glassware.

4.4.2. Weight displayed on balance is compared with weight shown on computer screen.

4.4.3. Balance calibration is checked before and after weighing.

4.4.4. Balance data are transferred to computer electronically.

4.4.5. Balances are professionally serviced at least once a year, balance calibrations are checked daily with Class $\mathbf{S}$ traceable weights, and the results documented. All servicing and balance calibrations are recorded in the balance logbook with corrective actions.

5. The filtration method.

5.1. Compare sample data on the worksheet with data on the fieldsample label and with the bottle tare value. Record errors on the worksheet and correct in edit option of program.

5.2. Place the crucible in crucible holder, wet filter, and apply suction to seat the filter.

5.3. Check crucible identification for agreement with container identification on worksheet.

5.4. Wash all sediment from the bottle into the crucible with deionized water. Use care not to spill any of the sample while transferring.

5.5. Place the crucibles in the oven. Dry them at $103{ }^{\circ} \mathrm{C}$ until all visible moisture is removed and continue to dry them for a minimum of 1 hour.

5.6. Quality-control measures. 
5.6.1. A second analyst is used to process the samples for filtering during training and routinely if possible. The label data, bottle tare, and crucible identification are compared with similar data on the worksheet.

6. The evaporation method.

6.1. Align evaporating dishes sequentially on countertop, identification facing analyst.

6.2. Compare sample data on the worksheet with data on the fieldsample label and with the bottle tare value. Record errors on the worksheet and correct using edit option of program.

6.3. Check dish identification for agreement with dish identification on worksheet.

6.4. Wash all sediment from the bottle into the dish using deionized water. Use a dish of sufficient volume to avoid spillage when transferring dish to oven.

6.5. Place evaporating dishes in oven. Dry at $80^{\circ} \mathrm{C}$ until all visible water is removed, then dry for an additional hour at $103{ }^{\circ} \mathrm{C}$. Evaporating dishes must be dried initially at a lower temperature to prevent spatter of the sediment from the dishes by boiling water.

7. For both methods, cool the containers in a desiccator to room temperature for a minimum of 3 hours.

\subsection{Quality-control measures.}

7.1.1. Desiccators are cleaned and new desiccant added or desiccant dried at least semiannually with the dates recorded in the desiccator logbook.

7.1.2. Color moisture indicator is used in all desiccators.
8. Stage 3 of the concentration program.--The containers plus dried sediment are weighed. Replace the lid on the desiccator after removing a sample for weighing. Weigh the sample to the nearest $0.0001 \mathrm{~g}$ on the analytical balance. The time spent between removing the sample from the desiccator and the weighing of the sample should not be more than 1 minute. Crucibles and dishes are transferred from the desiccator to the balance by using tongs, plastic gloves, or rubber fingertip pads.

\subsection{Quality-control measures.}

8.1.1. Protective devices are used when handling glassware.

8.1.2. Desiccator lid is replaced between the weighing of each container.

8.1.3. Each cruicible or evaporation dish is weighed within 1 minute of removal from desiccator.

9. Review, edit, initial, and date worksheet of concentration notes. Obtain a final print of concentration notes for review by the laboratory chief.

\section{Particle-Size Analysis}

Several methods of analyses can be used to determine the broad range of particle sizes $(0.001$ to $128 \mathrm{~mm}$ ) encountered in suspended-sediment and bed-material samples. The commonly used particle-size methods are sieve, visualaccumulation tube, pipet, bottom-withdrawal tube, hydrometer, and SediGraph. The bottomwithdrawal and hydrometer methods are not used in the Iowa District laboratory and are not discussed. This section outlines the bench-level protocols used in the various methods of particlesize analyses.

Most samples will require some type of preweighed container. Evaporating dishes, crucibles, and beakers that will be used during the sample analyses are preweighed using a software program called TARE. The program prompts for the entry of the container identification, and then for the weight of the container on the balance. The weights are stored 
in the computer which the SIZE program can access later during data entry. The number and types of containers that will be used are estimated. The containers are weighed and placed in a covered large oven pan until used. When a container is used, the identification number is recorded on the worksheet. Data entry for a sample normally is not done until analysis is complete.

\section{Dry-Sieve Method}

The dry-sieve method of analysis is used for sand and gravel samples weighing between 50 and $400 \mathrm{~g}$. The method as described closely follows the recommendations of Guy (1969) and Tyler Industrial Products (1976). The criteria for sieves and their testing are established by the American Society for Testing and Materials (1970).

1. Equipment required:

1.1. Nest of sieves covering the size range of material.

1.2. Rotap shaker.

\subsection{Computer}

1.4. Macro balance.

\section{Procedure:}

2.1. Separate the sand and gravel from the silt-clay fraction by wet sieving using deionized water if a pipet analysis of the fine material is required.

2.2. Air or oven dry the sand and gravel at $80^{\circ} \mathrm{C}$.

2.3. Weigh the sample. Split the sample if the weight is more than $400 \mathrm{~g}$, and weigh split sample for analysis. Retain 5 percent of the split samples as replicates.

2.4. Shake the sample for 20 minutes in a Rotap.

2.5. Enter the size-fraction weights retained on each sieve into the computer using the SIZE program. A data file for the sample was created during the sample login. The data file and the dry-sieve data entry are selected from the program menu. The material retained on each sieve from step 2.4. is weighed on the balance, and the computer program transfers the weight measurement electronically to the data file. After weighing of the material on the sieves has been completed, the program computes the final results of the analysis. The results are presented as "percent finer than" the largest size class as shown in figure 7. The weight of sample retained on each sieve divided by the total weight of the sample gives the sample "percent-size class." The "percent finer than" figure is computed on the basis that 100 percent of the sample is finer than the next larger size class than the largest size class with retained material. The "percent finer than" figure is computed starting with 100 "percent finer than" by subtracting each successive smaller size class "percent in class" from the larger size class "percent finer than" figure.

2.6. Compare the difference in weights of the total sample measured in steps 2.3 and 2.5, and determine sample loss or gain during the analysis.

3. Quality-control measures:

3.1. Reanalyze a sample if there is more than a 3-percent difference between initial weight and final weight.

3.2. Spot check the analytical procedures and correct if a deficiency is observed.

3.3. Reanalyze one sample in 20 or the sample-split fraction for quality control. If there is more than a 5percent difference in any size class, reanalyze the sample. The results for all size classes are compared. If agreement is not within 5 percent, the laboratory chief is notified before more samples are analyzed.

3.4. Record the number of samples that do not meet the criteria in 3.1. or 3.3 in the sieve logbook. If more than two 
USGS PARTICLE-SIZE SUMMARY SHEET 3.0

FILE : BM-9005-IA.DUN

LOCATION : SOUTH SKUNK RIVER @ COLFAX

STATION NO. : $05471050 \quad$ DATE : 891011 TIME : 0919

\section{GAGE HT ( $f t$ ) 6.77}

REMARKS : STA: 10-15-20-32-38; TOTAL NET WT BEFORE SIEVING - 317.0g

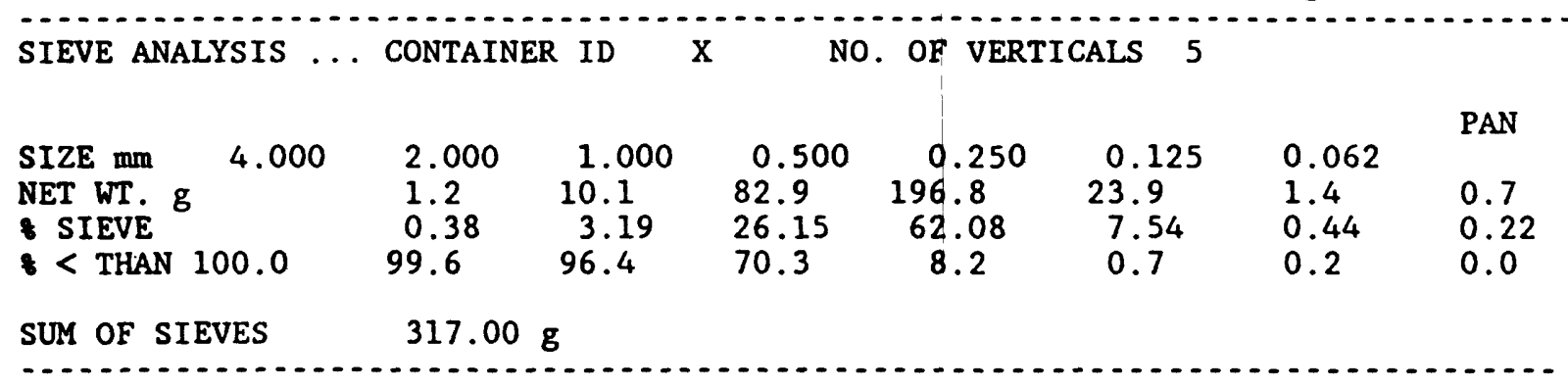

Figure 7. Example of computer-generated results for particle-size analysis of bed material using dry-sieve method.

consecutive samples do not meet either of these criteria, further analysis is discontinued until the cause of the discrepancy has been found and corrective action taken.

3.5. Check sieve screens daily and clean, replace, or repair as needed.

\section{Wet-Sieve Method}

The wet-sieve method is used to separate sand and coarser material from finer material.

1. Equipment required:

1.1. 3- or 8-in. sieve or sieves as required by sample size. A $0.062-\mathrm{mm}$ mesh sieve is all that is required for the separation of sand from finer material.

1.2. Deionized water.

1.3. Porcelain evaporating dishes and beakers.

1.4. Hand-held oscillator.

1.5. Computer.

1.6. A macro or analytical balance, depending on the quantity of sample.

2. Procedure:

2.1. Thoroughly wet the surface of the largest mesh sieve and immerse the sieve in the porcelain dish so that the screen is covered with $1 / 4$ in. of water.

2.2. The sample is washed onto the sieve, and the sieve is agitated vigorously in several directions. A hand-held oscillator may be used for this agitation. Two or three rinses are usually sufficient for all particles finer than the sieve to pass through the screen.

2.3 An alternate procedure may be used if the sand fraction is less than 20 percent of the total. This procedure is to rinse the screen with a gentle jet of water (gravity flow) to wash the particles across and through successively smaller sieves.

2.4. Steps 2.1 and 2.2 or 2.3 are repeated until all sieves have been processed.

2.5. The sample fractions are dried according to the methods listed in the 
“Concentration Analysis" section 6.5.

2.6. The sample fractions are weighed using the macro or analytical balance and the computer program.

3. Quality-control measures.

3.1 Five percent of the samples processed will be rinsed again and dried separately. If the total weight of the sample has changed by more than 3 percent, the equipment and analysis procedure will be checked.

3.2. Check sieve screens daily and clean, replace, or repair as needed.

\section{Visual-Accumulation-Tube Method}

The VA-tube is used for the analysis of sand sizes. The procedure described closely follows Guy (1969) and the Inter-Agency Committee on Water Resources (1958).

1. Equipment required:

1.1. VA-tube (fig. 8).

1.2. 600 - or 1,200 -mL beaker.

1.3. Sieves of $0.053-, 1.0-$, and $2.0-\mathrm{mm}$ mesh.

1.4. Evaporating dish.

1.5. Computer.

1.6 Analytical balance.

2. Sample preparation:

2.1. The initial preparation of the sample requires wet sieving and separation of material using a $0.053-\mathrm{mm}$ sieve. The $0.062-\mathrm{mm}$ size class will be determined by the VA-tube method. Depending upon the quantity and the size of the particles in the sample, a second separation is made. If more than $7 \mathrm{~g}$ of sand are to be analyzed, the 180-cm VA-tube is used, and the 2$\mathrm{mm}$ sieve is used for the coarse separation. If less than $7 \mathrm{~g}$ of sand are to be analyzed, the $120-\mathrm{cm}$ VA-tube is used, and the $1-\mathrm{mm}$ sieve is used for the coarse separation. Sediment coarser than these sizes is analyzed using the sieve methods. More information on tube selection is found in section 3.2.

2.2. Store the sand fraction for the VA-tube method in an evaporating dish. Add 40 to $50 \mathrm{~mL}$ of deionized water to cover the sample about $1 \mathrm{in}$. and add $10 \mathrm{~mL}$ of hydrogen peroxide to remove organic material (Guy, 1969). After the organic matter has been removed, store the sample in a covered dish with sufficient water to keep the sample saturated.

3. Tube selection:

3.1. Tube selection is made easier if samples are sorted visually in ascending or descending order as to

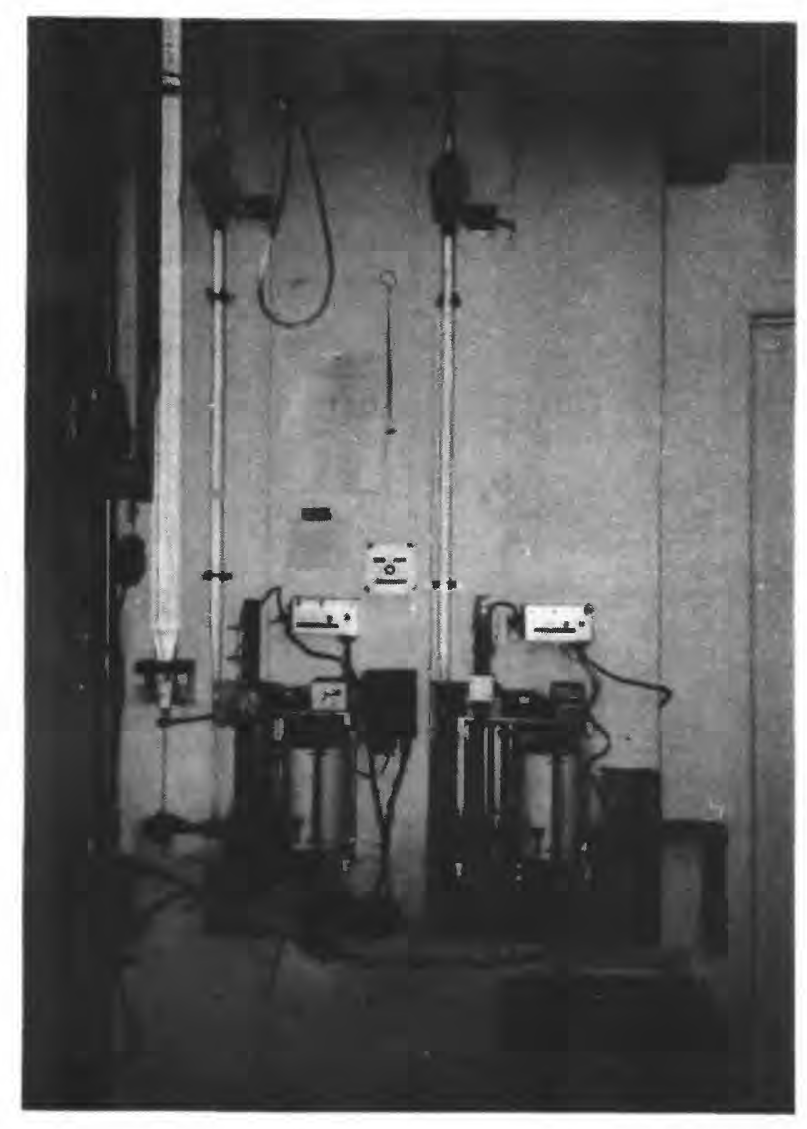

Figure 8. Visual-accumulation tubes with automatic tracking devices installed in laboratory. 
the quantity of sand in the sample.

3.2. To select the proper tube size, the table at the bottom of this page (Guy, 1969) is used together with an estimate of the sand weight and size.

4. To prepare the tube for use:

4.1. After selecting proper tube, dismantle tube components, wash with laboratory detergent, and rinse thoroughly with deionized water.

4.2. Reassemble components.

4.3. Align top and bottom reference marks with permanent wall alignment marks.

4.4. Open the upper valve of the VA-tube.

4.5. Fit the rubber stop plug in the bottom of the tube.

4.6. Fill the tube with deionized water to just above the upper valve.

4.7. Check tube for foreign material or retained sand.

4.8. Measure water temperature in the tube.

4.9. Turn on the light-control switch.

5. Placing chart on drum:
5.1. Push the drum-release lever down to rotate the drum until the paperholding brackets face forward.

5.2. Place the chart on the drum and secure brackets, rotate drum, and secure chart in brackets. Rotate drum and check that the chart is against the lower lip of the drum.

5.3. Lower the telescope hairline to the top of the plug.

5.4. Set the pen slightly above the chart baseline.

5.5. Rotate the drum to establish a new baseline.

5.6. Return the pen to $1 / 8 \mathrm{in}$. to the right of the zero time.

5.7. Turn on the forward switch to bring the pen exactly on the zero time line.

5.8. Recheck the telescope hair line (top of plug alignment).

5.9. Close the upper valve.

6. Analysis procedure:

6.1. Compare VA dish identification on worksheet with VA dish identification and unique number on VA graph.

6.2. Rinse sample into tube with deionized

\begin{tabular}{|c|c|c|c|c|c|}
\hline \multicolumn{2}{|c|}{ SAMPLE } & \multicolumn{2}{|c|}{ MAXIMUM PARTICLE SIZE } & \multicolumn{2}{|c|}{ TUBE SIZE } \\
\hline $\begin{array}{l}\text { Dry weight } \\
\text { (grams) }\end{array}$ & $\begin{array}{l}\text { Volume of sand } \\
\text { (milliliters) }\end{array}$ & $\begin{array}{c}\text { Fall } \\
\text { diameter } \\
\text { (milliliters) }\end{array}$ & $\begin{array}{c}\text { Sieve } \\
\text { diameter } \\
\text { (milliliters) }\end{array}$ & $\begin{array}{c}\text { Tube } \\
\text { length } \\
\text { (centimeters) }\end{array}$ & $\begin{array}{l}\text { Accumulation } \\
\text { chamber } \\
\text { diameter } \\
\text { (millimeters) }\end{array}$ \\
\hline $0.05-0.8$ & $0.03-0.5$ & 0.25 & 0.25 & 120 & 2.1 \\
\hline $0.4-2.0$ & $0.2-1.2$ & .35 & .40 & 120 & 3.4 \\
\hline $0.8-4.0$ & $0.5-2.4$ & .50 & .60 & 120 & 5.0 \\
\hline $1.6-6.0$ & $1.0-4.0$ & .70 & 1.00 & 120 & 7.0 \\
\hline $5.0-15.0$ & $3.0-9.0$ & 1.00 & 2.00 & 180 & 10.0 \\
\hline
\end{tabular}


water and fill tube with deionized water to the reference line on top funnel.

\subsection{Turn on the tapper switch.}

6.4. Mix the sample vigorously with the mixing rod until the sample is well dispersed and then open the upper valve.

6.5. The most critical time during the tracking of the sample is when the coarser particles begin to accumulate, or during the first 30 seconds that the particles fall. The path of the automatic tracker must be checked during this time. Only occasional inspection of the tracking is required if the tracking is satisfactory.

6.6. When the pen reaches the water temperature line on the chart in the $0.625 \mathrm{~mm}$ range that corresponds with the temperature of the water in the tube, turn off the forward switch, immediately close the upper valve, rotate the drum to draw a top reference line at the height of the accumulated sediment, move the eyepiece upward, remove the bottom plug, and remove the accumulated sample.

6.7. Drain the tube completely, rinse the remaining residue in the tube into an appropriately sized beaker, and let the residue settle. This residue will be returned to the fraction that is finer than $0.053 \mathrm{~mm}$ for further analysis or it will be dried and then weighed. This weight is added to the non-analyzed part of the sample that is finer than $0.053 \mathrm{~mm}$.

6.8. Process next sample beginning with step 5 , placing chart on drum.

6.9. An automatic analog-to-digital conversion unit displays on a printer terminal the sample percentages to be used in the computations. These values are recorded on the worksheet and entered in the appropriate computer program.

7. Completing the analysis:

7.1. Place the evaporating dish in oven. Dry evaporating dishes at $80^{\circ} \mathrm{C}$ until all visible water is removed, and then dry for an additional hour at $103^{\circ} \mathrm{C}$.

7.2. Weigh the VA-sample fraction using an analytical balance and the "VA Dish Entry" option of the computer program.

8. Quality-control measures:

8.1. Reanalyze one sample each day the VA-tube analyses are done. If the analysis varies by more than 5 percent or more in any size class, it is reanalyzed. If agreement is not within 5 percent for any size class, the sample analysis is discontinued until the deficiency is corrected. Record in VA-tube logbook the sample number, the agreement within the limits, and corrective action, if needed.

8.2. The laboratory chief spot checks the analytical procedure each day VAtube analyses are done by reanalyzing a sample. If the sample varies by more than 5 percent in any size class, it is reanalyzed. If agreement is not within 5 percent for any size class, discontinue sample analysis until the deficiency is corrected. Record in VAtube logbook the sample number, the agreement within the limits, and corrective action taken.

8.3. Drain the tube and rinse with deionized water between each analysis.

8.4. Wash the tube with detergent and flush with deionized water each day it is used.

8.5. Check alignment of reference marks each day the tube is used.

8.6. Time synchronize motors each day the VA-tube is used and record the results in the VA-tube logbook. 
8.7. The analyzed sample is dried, cooled, and weighed as described in 7.1. and 7.2.

\section{Pipet Method}

Pipet analysis is used to determine the particle sizes of material in the $0.002-0.062 \mathrm{~mm}$ range. The pipet method is used for the particlesize analysis of both suspended-sediment and bed-material samples. The suspended-sediment sample requires the determination of the sample concentration in addition to any particle-size analysis. To determine the concentration of the sample, the total weight of the water-sediment mixture is determined before any other analytical processing. This is normally done during the login of the sample, and the weight is stored in the data file by the computer program.

If colloidal material or glacial flour is present, the specific conductance of the supernatant water is measured, and a dissolvedsolids correction in milligrams per liter is determined. One-hundred $\mathrm{mL}$ of the supernatant water are decanted and dried. A dissolved-solids correction in milligrams per liter is determined for the decanted supernatant. If the results show that colloidal or glacial material is the cause of the dissolved solids in the supernatant water, a correction factor is computed to be applied to the material finer that $0.002 \mathrm{~mm}$. The pipetwithdrawal schedule and the method procedure closely follow Guy (1969).

\section{Equipment required:}

1.1. A pipet rack with a constanttemperature water bath.

1.2. A pipet with a marked rated volume or computed volume.

1.3. A vacuum system.

1.4. A deionized-water supply.

1.5. A malt mixer and soil-dispersion cups.

1.6. A stopwatch or a timer clock with sweep second hand.

1.7. Evaporating dishes (one for each required withdrawal).

1.8. Sedimentation cylinders of various volumes from 250 to $1,200 \mathrm{~mL}$ capacity.

\section{Preparation for analysis:}

2.1. Using the wet-sieve method discussed earlier, the sample is sieved with a 0.053-mm mesh sieve. If sufficient material is present, the particle size of the sand is determined using the VAtube method.

2.2. If the quantity of sand is insufficient for a VA-tube analysis, the sample is wet sieved with a $0.062-\mathrm{mm}$ mesh sieve. The material larger than 0.062 $\mathrm{mm}$ is retained on the sieve, rinsed into an evaporating dish, and is oven dried at $80^{\circ} \mathrm{C}$ until all visible water is removed, and then dried for an additional hour at $103^{\circ} \mathrm{C}$.

2.3. The sedimentation cylinder should contain a sediment concentration from 2,000-5,000 mg/L (Guy, 1969). Concentrations as small as 1,000 $\mathrm{mg} / \mathrm{L}$ are acceptable at the request of the customer. The material that passes through the sieve as described in sections 2.1 and 2.2 is placed in a $1,000-\mathrm{mL}$ or smaller graduated beaker. The sample is diluted with deionized water. The volume of water in the beaker is noted, and the beaker is placed on a magnetic stirrer for 5 minutes after which a pipet withdrawal is made. This aliquot is used to determine the optimum cylinder volume for the analysis. The aliquot is dried, cooled, and then weighed on the analytical balance. The weight is stored in the data file by the computer program. A list of the sample volumes and corresponding concentrations in milligrams per liter is displayed on the computer screen. The optimum-size cylinder for the sample is selected from the list.

2.4. The sample settles for 10 to 14 days or until the supernatant water is clear. The sample then is ready for analysis.

3. Procedure for analysis: 
3.1. The supernatant water is siphoned off the sample, taking care not to disturb the settled sediment.

3.2. The dispersing agent is prepared as described in Guy (1969). It is added to the sample at a ratio of $1 \mathrm{~mL}$ agent per $100 \mathrm{~mL}$ of sample.

\subsubsection{The supply of dispersant is kept in an amber bottle or stored in a closed dark cabinet.}

3.2.2. The dispersant is discarded if it becomes cloudy.

\subsubsection{The dispersant $\mathrm{pH}$ should be between 9.0 and 9.5. If the $\mathrm{pH}$ is lower than 9.0, the dispersant is discarded.}

3.3. The soil-dispersion cup is placed on the mixer and stirred for 5 minutes.

3.4. The sample is rinsed into the sedimentation cylinder and placed in the water-bath pipet rack.

3.5. Glassware for the analysis has been weighed using the balance and the pipet-tare option of the computer program. The weighed glassware is placed with the appropriate sample on the pipet rack. The glassware identification is checked with that recorded on the worksheet.

3.6. The first two withdrawals from a cylinder are used to determine the sediment concentration in the cylinder. The sample in the first cylinder is stirred for 1 minute using a hand stirrer. A pipet withdrawal at a $15-\mathrm{cm}$ immersion depth is made immediately after stirring. The withdrawn aliquot is rinsed from the pipet into the first dish. The first cylinder is again stirred for 1 minute, and a pipet withdrawal is made at 15 $\mathrm{cm}$. The pipet aliquot is rinsed into the second dish. This process of obtaining the concentration withdrawals is continued for the remaining cylinders.

3.7. A pipet-withdrawal schedule showing the withdrawal times to determine standard U.S. Geological Survey particle-size classes for material with a specific gravity of $2.65 \mathrm{gm} / \mathrm{cm}^{3}$ (grams per cubic centimeter) is shown in Guy (1969). The times of the scheduled withdrawals are based on the temperature of the sample in the cylinder, specific gravity of the material, withdrawal depth of the pipet, and the particle size to be determined.

3.8. The temperatures of the samples in the cylinders are measured. The temperature is used to select the first withdrawal time and depth from the pipet-withdrawal schedule for the beginning size class. The first sample is stirred with the hand stirrer for 1 minute, and a stopwatch is started to time the analysis for the pipet withdrawals. If two analysts are present, withdrawals can be made by one analyst while the samples in the cylinders are stirred at 2-minute intervals by the other analyst. The analyses can be done by one person. After 1 minute the second cylinder is stirred. Each cylinder is sequentially stirred at 2-minute intervals remembering to start the stopwatch at the end of the 1-minute stirring cycle. Once the stopwatch is started the time is continuous.

3.9. The withdrawal time on the schedule is the mean time of withdrawal. For example, if it takes 12 seconds to fill the pipet, the schedule shows that to make a withdrawal for the $16-\mu \mathrm{m}$ size at a temperature of $28^{\circ} \mathrm{C}$, the pipet is immersed to a depth of $10 \mathrm{~cm}$, and the time for the withdrawal is 6 minutes and 22 seconds; however, the actual time of beginning the withdrawal would be 6 minutes and 16 seconds.

3.10. The procedure is continued until all withdrawals are made. The samples are oven dried at $80^{\circ} \mathrm{C}$ until all visible water is removed, then dried for an additional hour at $103^{\circ} \mathrm{C}$. The dishes are weighed using the analytical 
balance and the appropriate computer program. A final computer printout of the analysis can be obtained at this time.

\section{Computations:}

4.1. The procedure for determining the sediment concentration discussed in step 3.6. is to first subtract the dispersing-agent correction factor from each dish.

4.1.1. The dispersing-agent correction factor is determined by setting up two 500-mL graduated cylinders filled to $500 \mathrm{~mL}$ with deionized water and adding 5 $\mathrm{mL}$ of dispersing agent to each cylinder. Four pipet withdrawals are made from each cylinder and retained in pretared evaporating dishes. The dishes are oven dried, cooled, and then weighed on the analytical balance. The high and low weights are not used. The remaining weights are averaged for the dispersingagent correction factor. If the pipet is replaced or the dispersing agent supply is replaced, the correction factor is recomputed.

4.2. In most pipet analysis the first two dish withdrawals are used to determine the sediment concentration in the sedimentation cylinder. These withdrawals are made from a dispersed system and should be representative of the sediment concentration in the sedimentation cylinder. For example, the weight of the material in dish 1 is $0.1014 \mathrm{~g}$, in dish 2 is $0.01008 \mathrm{~g}$, and the computed dispersing-agent correction is $\mathbf{0 . 0 1 0 6}$. The net weight of the sediment for dish 1 is $0.0908 \mathrm{~g}$ and for dish 2 is $0.0902 \mathrm{~g}$. The mean weight of the sediment for dishes 1 and 2 is 0.0905 $\mathrm{g}$. The relation between the volume of the pipet and the sedimentation cylinder is called the pipet-volume factor. The pipet-volume factor is determined by dividing the volume of the sedimentation cylinder by the volume of the pipet. The pipet-volume factor using a $500-\mathrm{mL}$ sedimentation cylinder and a $25-\mathrm{mL}$ pipet is 20 . The weight of the sediment in the sedimentation cylinder should equal the mean weight of the sediment determined from the first two withdrawals times the pipet-volume factor, which is $1.81 \mathrm{~g}$. The sedimentation-cylinder concentration is the weight of the sediment, $1.81 \mathrm{~g}$, divided by the weight of the watersediment mixture, $500 \mathrm{~g}$, times $1,000,000$. The result is the concentration expressed in parts per million (ppm) and is $3,620 \mathrm{ppm}$. The weight of the sediment from the pipet analysis is added to the weight from the other sample fractions, and the sum of these weights is the total weight of sediment for a sample. The results of the sample concentration are reported in milligrams per liter $(\mathrm{mg} / \mathrm{L})$ and are considered equal below $8,000 \mathrm{ppm}$ or a conversion factor applied above this value (Edwards and Glysson, 1988). The results of a complete particle-size analysis are shown in figure 9.

A second method of obtaining the total weight of the sediment in the pipet also can be used. It can be used as an independent check on the accuracy of the first method. It is also useful for analyzing samples that have to be analyzed in sedimentation cylinders of less than $400 \mathrm{~mL}$ where three or more withdrawals are required to determine the particle size. In this second method, the first two withdrawals for concentration are not required as in the first method. After completion of the withdrawals for particle-size, the material remaining in the cylinder is dried and weighed. The weight from the cylinder is added to the weight from the particle-size withdrawals from the cylinder and the weight correction for the dispersing agent is subtracted. 
5. Quality-control measures:

5.1. An aliquot sample is obtained for optimum cylinder size.

5.2. Glassware sequence is rechecked.

5.3. Withdrawal residues are weighed and stored electronically in the data file.
5.4. One in 10 samples is split into replicate samples and analyzed. Samples are selected and reviewed by the laboratory chief.

5.5. Concentration values are compared with those of replicate samples. Values within 10 percent are acceptable. If the difference is more

USGS PARTICLE-SIZE SUMMARY SHEET 3.0

FILE : SI-8802-IA.DUN*

LOCATION : IOWA RIVER @ WAPELLO

STATION NO. : 05465500

Q (cfs) $\quad 8,160.00$

SAMPLES

\begin{tabular}{|c|c|c|c|c|c|c|c|}
\hline $\begin{array}{l}\text { XSECTION } \\
\operatorname{NET}(g)\end{array}$ & $\begin{array}{r}800-860 \\
544.0\end{array}$ & $\begin{array}{r}880-900 \\
683.5\end{array}$ & $\begin{array}{r}920-960 \\
797.8\end{array}$ & $\begin{array}{r}980 \\
600.1\end{array}$ & $\begin{array}{r}1000 \times 2 \\
542.7\end{array}$ & $\begin{array}{r}1020 \\
539.6\end{array}$ & $\begin{array}{r}1040 \\
673.2\end{array}$ \\
\hline $\begin{array}{l}\text { XSECTION } \\
\operatorname{NET}(g)\end{array}$ & $\begin{array}{r}1060 \\
725.1\end{array}$ & $\begin{array}{r}1080 \\
763.3\end{array}$ & $\begin{array}{r}1100 \\
630.7\end{array}$ & $\begin{array}{r}1120-1140 \\
670.9\end{array}$ & & & \\
\hline $\begin{array}{l}\text { SAMPLE NET } \\
\text { CONC. }\end{array}$ & $\begin{array}{l}7170.9 \mathrm{~g} \\
278 \mathrm{mg} / \mathrm{L}\end{array}$ & $\begin{array}{r}\text { TOTAI } \\
(80154)\end{array}$ & SEDIMENT & 1.9905 & g & & \\
\hline
\end{tabular}

VA TUBE

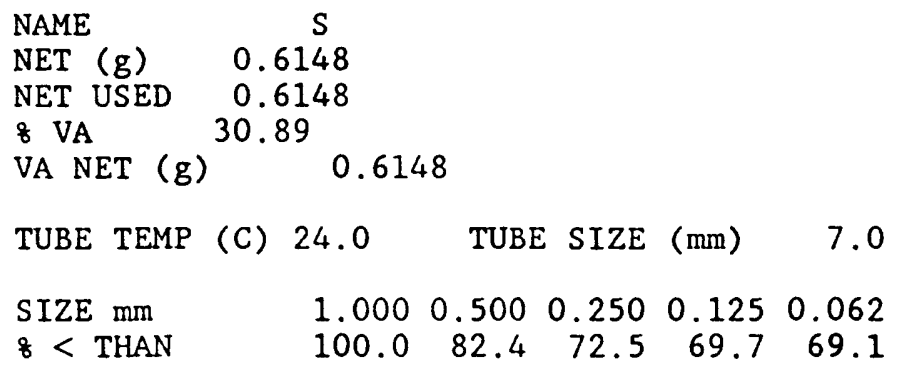

PIPET ANALYSIS

BEGIN TEMP : $27.0 \mathrm{C}$

END TEMP : $27.0 \mathrm{C}$

CYLINDER VOL (mL): 400 DISP. AGENT : $0.0103 \mathrm{gm} \mathrm{PIPET} \mathrm{VOL.} \mathrm{:} 24.8600 \mathrm{~mL}$

$\begin{array}{llllcccc}\text { SIZE mm } & \text { CONC } & \text { CONC } & 0.031 & 0.016 & 0.008 & 0.004 & 0.002 \\ \text { NAME } & \text { W31 } & \text { W32 } & & \text { W34 } & \text { W35 } & \text { W36 } & \text { W37 } \\ \text { NET SED }(\mathrm{g}) & 0.0963 & 0.0952 & & 0.0721 & 0.0561 & 0.0487 & 0.0408 \\ \text { FINETHAN }(\mathrm{g}) & 1.3757 & & 0.9944 & 0.7369 & 0.6179 & 0.4907 \\ \text { \& } \quad \text { THAN } & & & 50.0 & 37.0 & 31.0 & 24.7\end{array}$

PIPET CONCENTRATION $3440 \mathrm{ppm}$

Figure 9. Example of computer-generated results for complete particle-size analysis of suspended sediment using pipet and visual-accumulation-tube methods. 
than 10 percent, it is recorded on the sample results.

5.6. Reference samples are analyzed as scheduled.

\section{SediGraph Method}

The SediGraph method is an automated method of analyzing particles in the size range of 0.062 to $0.001 \mathrm{~mm}$. At this time the method is used only for research or special request analysis. A correction procedure is used for samples with material coarser than $0.045 \mathrm{~mm}$. When analyzing samples with the SediGraph, care must be used if organic materials are present. Organic material affects the density of the material and causes stratification of the sample in the cell chamber. Samples from lakebeds commonly contain sufficient organic material to cause analytical problems; samples from streams generally do not cause problems. The method for removal of the organic material in the fine fraction is similar to the method for sand fraction described for the VA-tube method 2.2 (Guy, 1969). The use of hydrogen peroxide may dissolve or destroy the clay fraction and is used only on a sample-by-sample basis.

1. Equipment required:

1.1. SediGraph unit and graph paper.

1.2. Glass or plastic beakers of various sizes, 50 to $1,000 \mathrm{~mL}$.

\subsection{Ultrasonic bath.}

2. Sample preparation: The same as for the pipet analysis.

\section{Procedure for analysis:}

3.1. Decant clear water from the sample. Depending on the size of the container used during the settling process and the quantity of sample, the sample may be transferred to a smaller graduated container. The dispersing agent is added at the ratio of $1 \mathrm{~mL}$ of agent to $100 \mathrm{~mL}$ of sample (Guy, 1969).

3.2. Set the sample in the ultrasonic bath and agitate for 15 minutes. This procedure replaces the mechanical stirring in the pipet method.

3.3. To set the zero baseline on the graph use a base solution of $1 \mathrm{~mL}$ of dispersing agent per $100 \mathrm{~mL}$ of deionized water. Place new SediGraph graph paper on unit. Start circulating pump and fill sample cell; check for air bubles, and turn pump off. Place the sample cell in samplecell holder and close the cell-chamber door. Set the SediGraph pen on the zero baseline of the graph paper.

3.4. Perform a cell-window and beam-split test, which is a quality-control test of the SediGraph mechanical and electronic system using the base solution (Micromeritics, 1982). If the pen track varies by more than \pm 1.5 percent from the zero baseline on the chart, or if the beam-split value differs by more than 3 percent from the beam-intensity half value, adjust the SediGraph and rerun test.

3.5 . Place the sample container in the cell chamber, place a magnetic stirring bar in the sample, place the pump lines in the sample, turn on the magnetic stirrer.

3.6. Turn on the pump and circulate the sample through the sample cell. Inspect the cell for air bubbles. Place the sample cell in the holder, measure the sample temperature, and close cell-chamber door.

3.7. Mount the analog chart in SediGraph chart bracket. Set the SediGraph pen to the 100-percent line on the analog chart using the 100-percent dial.

3.8. The sample concentration may have to be decreased with diluted dispersing agent so that the setting on the 100 percent dial of the SediGraph reads in the range of 85 to 100 . The 100 percent dial is an instrumentsensitivity adjustment. Smallconcentration samples can be analyzed as low as a 50 -percent pen setting on the analog chart with an acceptable loss of precision. 
3.9. Obtain temperature of the sample, set the SediGraph RATE switch, and recheck the sample cell for air bubbles. A worksheet is supplied by Micromeritics for computing the rate settings for the SediGraph. Rate settings for sediment for a range of temperatures 25 to $33^{\circ} \mathrm{C}$ have been computed.

3.10. Close cell-chamber door and when the pen has stabilized, reinspect the pen setting with the chart startingpercent line, adjust 100 -percent dial as needed, and turn on the start switch.

3.11. At completion of analysis, remove graph and record temperature, rate, starting percentage, and volume of sample. Check sample and container identification with that recorded on graph.

4. Quality-control measures:

4.1. The manufacturer's sample-cell check and beam-split test are done each day samples are run.

4.2. At least one sample in 10 is reanalyzed. If results do not agree to within 5 percent for all size classes, reanalyze sample. If results are not within 5 percent for all size classes, the laboratory chief is notified before more samples are analyzed.

4.3. Zero-percent graph setting is checked with base solution in the cell every 10 analyses.

4.4. The calibration with the garnet reference sample is checked after processing 50 samples. If calibration does not agree within \pm 1.5 percent, the instrument is recalibrated as explained in the instruction manual (Micromeritics, 1982). Rerun garnet sample. If reference sample is still more than 3 percent, Micromeritics is called for service.

4.5. One sample in 10 is reanalyzed using pipet method. Analysis agreement should be within 5 percent at any size class. If agreement is not within 5 percent, the laboratory chief is notified.

\section{INTERNAL QUALITY-ASSURANCE AND QUALITY-CONTROL PROCEDURES}

\section{Login Records}

A logbook of the computer-generated directory copies is maintained for all samples received by the laboratory for concentration determination. Logbooks of the unique numbers used for sample identification for particle-size samples are also maintained.

\section{Check Samples}

Normally, 5 to 10 percent of the samples analyzed by the laboratory will be qualityassurance samples inserted by the analyst or the laboratory chief in addition to the qualityassurance samples from the customers. These samples consist of field-collected replicate samples, blank samples, and repetitive analyses. Blank samples are prepared from deionized water and will be distributed throughout the set of concentration-analysis samples. These samples will be clearly marked as quality-control samples. Presently (1990), the U.S. Geological Survey is working with the American Society for Testing and Materials to develop standard reference samples to use in the laboratory. The laboratory is provided with a copy of the qualitycontrol samples for a log record from the computer. Analyses from the quality-control samples are reviewed by the laboratory chief and the supervisor. Corrective action will be taken as required. The notes of these corrective actions are retained in the quality-control logbook.

\section{Data Procedures}

The results of the analyses are reported on computer-generated forms and are reviewed for errors before submitting them to the laboratory chief. The remarks section includes comments concerning the sample, such as the presence of algae, unusual quantities of sand and sediment, or unidentified material observed in the samples. Results of the quality-control samples are supplied to the customers annually. If problems 
arise with regard to sample shipment, copies of the field-shipment $\log$ forms are retained until the analyses are complete. The customer is notified as soon as a problem is identified. Fieldshipment and field-log forms and notes made regarding samples are routinely returned to the customer with the analyses. The laboratory chief reviews, initials, and dates all analyses. All problems are resolved and documented before results of analyses are sent to the customer.

\section{Computer-Software Procedures}

The computer program developed by the Iowa District of the U.S. Geological Survey is the primary program used in several Survey sediment laboratories. Documentation for this program is available from the Iowa District. The Iowa District maintains a record of laboratories using these programs and will provide revisions to these laboratories. Only the system administrator, district sediment specialist, laboratory chief, and laboratory staff have access rights to the sediment-laboratory data files.

Data are backed-up on magnetic tape at least once a week. To avoid loss of data during a computer failure, a worksheet copy is made after stage 2 of the concentration program and a final formatted copy upon the completion of stage 3 of the program. At the end of the water year, which begins on October 1 and continues to September 30 of the next calendar year, the data files are archived on magnetic tape.

\section{Annual Quality-Control Report}

A summary report of the quality-control and quality-assurance program of the sediment laboratory is required annually. This report summarizes all quality-control samples analyzed by the laboratory and also includes all records of proficiency testing of laboratory personnel. Corrective actions are documented.

\section{TRAINING}

The training program for new staff members increases productivity and proficiency in sediment-laboratory techniques and the use of the computer programs. The laboratory employs college students on various government and school-work appointments. The training period normally lasts 8 to 16 weeks, depending on the work schedule of the employee. The following is a typical schedule for training.

1. During the first week the employee is given a tour of the laboratory and is shown the various analytical processes done in the laboratory. The field equipment for the collection of sediment samples is shown, and the various types of sampling are explained. The procedures using the equipment and the computer concentration program and login of samples are demonstrated.

1.1. The employee works in the concentration laboratory for 2 to 4 weeks under the supervision of the laboratory chief.

1.2. The work of the employee is reviewed carefully, and the laboratory requirements at the time are considered.

1.3. The next 4 to 8 weeks are used to increase the proficiency and productivity of the employee. The work is reviewed weekly by the laboratory chief, and recommendations for further training are discussed with the laboratory supervisor.

2. During the first year in the laboratory, the employee is taken to a sampling station and the sediment-sampling equipment is demonstrated and used. The basic procedures for computing a daily sediment record are explained.

3. After the employee has 9 to 12 months experience, training on particle-size analyses is given. This includes all or part of the following methods depending on laboratory requirements: dry and wet sieve, visual-accumulation tube, pipet, and SediGraph. Other training includes sample preparation, splitting, and removal of organic material. 


\section{SELECTED REFERENCES}

American Society of Civil Engineers, 1975, Sedimentation engineering: American Society of Civil Engineers Task Committee for the Preparation of the Manual on Sedimentation of the Sedimentation Committee of the Hydraulics Division, Manuals and Reports on Engineering Practice 54, 745 p.

American Society for Testing and Materials, 1970, Standard specifications for sieves for testing purposes: American Society for Testing and Materials Standards, American Society Testing Materials Designation E-1170.

Edwards, T.K., and Glysson, G.D., 1988, Field methods for measurement of fluvial sediment: U.S. Geological Survey Open-File Report 86-531, 118 p.

Friedman, L.C., and Erdmann, D.E., 1982, Quality assurance practices for the chemical and biological analyses of water and fluvial sediments: U.S. Geological Survey Techniques of Water-Resources Investigations, Book 5, Chapter A6, 181 p.
Guy, H.P., 1969, Laboratory theory and methods for sediment analysis: U.S. Geological Survey Techniques of Water-Resources Investigations, Book 5, Chapter C1, 58 p.

Guy, H.P., and Norman, V.W., 1970, Field methods for measurement of fluvial sediment: U.S. Geological Survey Techniques of Water-Resources Investigations, Book 3, Chapter C2, 59 p.

Inter-Agency Committee on Water Resources, Subcommittee on Sedimentation, 1958, Operator's manual on the visualaccumulation-tube method for sedimentation analysis of sands, in Report $\mathrm{K}$ of $\mathrm{A}$ study of methods used in measurement and analysis of sediment loads in streams: $28 \mathrm{p}$.

Micromeritics, 1982, Instruction manual SediGraph 5000D particle size analyser (with X-ray shutter): Norcross, Georgia, MIC P/N, 500/42804/00, 69 p.

Tyler Industrial Products, 1976, Testing sieves and their uses: Cleveland, Ohio, W.S. Tyler Co., Handbook 53, 48 p. 